\title{
Meta-Analysis of Drug Delivery Approaches for Treating Intracellular Infections
}

\author{
Sooyoung Shin ${ }^{1,2} \cdot$ Soonbum $\mathrm{Kwon}^{3} \cdot$ Yoon $\mathrm{Yeo}^{3,4}$ (1)
}

Received: 29 November 2021 / Accepted: 1 February 2022 / Published online: 10 February 2022

(c) The Author(s), under exclusive licence to Springer Science+Business Media, LLC, part of Springer Nature 2022

\begin{abstract}
This meta-analysis aims to evaluate the trend, methodological quality and completeness of studies on intracellular delivery of antimicrobial agents. PubMed, Embase, and reference lists of related reviews were searched to identify original articles that evaluated carrier-mediated intracellular delivery and pharmacodynamics (PD) of antimicrobial therapeutics against intracellular pathogens in vitro and/or in vivo. A total of 99 studies were included in the analysis. The most commonly targeted intracellular pathogens were bacteria (62.6\%), followed by viruses (16.2\%) and parasites (15.2\%). Twenty-one out of $99(21.2 \%)$ studies performed neither microscopic imaging nor flow cytometric analysis to verify that the carrier particles are present in the infected cells. Only $31.3 \%$ of studies provided comparative inhibitory concentrations against a free drug control. Approximately $8 \%$ of studies, albeit claimed for intracellular delivery of antimicrobial therapeutics, did not provide any experimental data such as microscopic imaging, flow cytometry, and in vitro PD. Future research on intracellular delivery of antimicrobial agents needs to improve the methodological quality and completeness of supporting data in order to facilitate clinical translation of intracellular delivery platforms for antimicrobial therapeutics.
\end{abstract}

Keywords Antimicrobials · Drug carriers · Intracellular drug delivery $\cdot$ Intracellular pathogens

\begin{tabular}{llll}
\multicolumn{2}{l}{ Abbreviations } & MIC & Minimum inhibitory concentration \\
MDR & Multidrug resistant & $\mathrm{IC}_{50}$ & Half maximal inhibitory concentration \\
XDR & Extensively drug resistant & $\mathrm{EC}_{50}$ & Half maximal effective concentration \\
mRNA & Messenger ribonucleic acid & MRSA & Methicillin-resistant Staphylococcus aureus \\
COVID & Coronavirus disease & PEG-PLGA & $\begin{array}{l}\text { Poly(ethylene } \\
\text { glycol)-block-poly(lactide-co-glycolide) }\end{array}$ \\
siRNA & Small interfering ribonucleic acid & & Percentage injected dose \\
PD & Pharmacodynamic & $\%$ ID & Reticuloendothelial system \\
CFUs & Colony forming units & RES &
\end{tabular}

Sooyoung Shin

syshin@ajou.ac.kr

Yoon Yeo

yyeo@purdue.edu

1 College of Pharmacy, Ajou University, Suwon, Gyeonggi-do 16499, Republic of Korea

2 Research Institute of Pharmaceutical Science and Technology (RIPST), Ajou University, Suwon, Gyeonggi-do 16499, Republic of Korea

3 Department of Industrial and Physical Pharmacy, College of Pharmacy, Purdue University, 575 Stadium Mall Dr., West Lafayette, IN 47906, USA

4 Weldon School of Biomedical Engineering, Purdue University, 206 S Martin Jischke Dr., West Lafayette, IN 47907, USA

\section{Introduction}

Infectious disease and antimicrobial resistance remain a major threat to the public health (1). Of many causative organisms, intracellular pathogens have become a source of great concern worldwide. Intracellular pathogens have developed immune evasion strategies over evolution (2). For example, some pathogens infect macrophages, which are responsible for the eradication of invading pathogens from the host, and rather turn them to their sanctuaries to evade the host immunity $(3,4)$. Consequently, intracellular infection caused by these organisms can often incur chronic, recurrent, or disseminated infections (5). Repeated and prolonged exposure to antimicrobials also increases the risk of 
turning these pathogens into multidrug resistant (MDR) or extensively drug resistant (XDR) organisms (6). Given the limited therapeutic options available and the paucity of novel antimicrobial agents in the pipeline, we face dire prospects in the global fight against intracellular infections.

To kill these pathogens, it is necessary to develop new strategies to deliver antimicrobial agents intracellularly. Ideally, antimicrobial therapeutics should selectively enter the infected cells, traffic in the cells to the desired intracellular niche (e.g., cytoplasm or vacuole) harboring pathogens, and kill the pathogens in a timely manner. The drug delivery field has a unique opportunity here, based on the knowledge obtained from the intracellular delivery of anti-cancer drugs or gene therapeutics (e.g., lipid nanoparticles of messenger ribonucleic acid (mRNA) encoding spike proteins for Coronavirus disease (COVID) vaccines (7)). In particular, gene therapeutics can contribute significantly to the therapy of intracellular infections. For example, viral infections pose further challenges to public health due to the capacity of viruses to spread and rapidly mutate rendering existing antiviral agents ineffective $(7,8)$. Small interfering ribonucleic acids (siRNAs) are potentially useful for the development of antiviral therapy as they can be designed to adapt to genetic changes in microorganisms and address the affected populations in a timely manner (9). With the approval of mRNA COVID vaccines, we foresee accelerated development of novel products based on advanced antimicrobial agents such as siRNA for therapy of intracellular infections. Therefore, it is a prime time to review current drug carriers targeted to intracellular pathogens and understand the achievements, limitations, and opportunities.

A wide variety of carrier systems have been investigated in the literature, ranging from nanoparticles, microparticles, live cell derivatives, prodrugs, or drug conjugates. Many studies employ particles as a carrier of antimicrobial agents, exploiting the ability of host cells (mostly macrophages) to endocytose them. The particles are made of organic or inorganic compounds that can encapsulate antimicrobial agents, in a size conducive to cellular uptake. Since mammalian cells take up particles via dedicated endocytosis pathways, the encapsulated drugs may bypass diffusional barrier imposed by the cell membrane (10) (Fig. 1). Ninety-nine papers on this topic were published in the past decade, with $89.9 \%$ of them in the last 10 years. However, there are only a limited number of commercial products based on the intracellular drug delivery approach, with silver nanoparticles being the most widely studied nanoparticles (11).

In this study, we aim to better understand the current landscape of drug delivery systems targeted to intracellular pathogens and potential barriers in their clinical translation. We performed a meta-analysis of literature concerning drug-loaded platforms targeting intracellular pathogens and reviewed study methodologies for evaluating their intracellular delivery and antimicrobial efficacy. Previous metaanalyses on drug-loaded platforms have primarily focused on anticancer therapy $(12,13)$. To the best of our knowledge, the present study is the first meta-analysis on carrier-mediated delivery of antimicrobial therapeutics against intracellular pathogens.

\section{Materials and Methods}

\section{Data Source and Search Strategy}

A literature search of PubMed and Embase was performed to identify original articles that evaluated carrier-mediated intracellular delivery and/or antimicrobial efficacy of
Fig. 1 Intracellular delivery of antimicrobial-loaded carriers. Created with BioRender.com

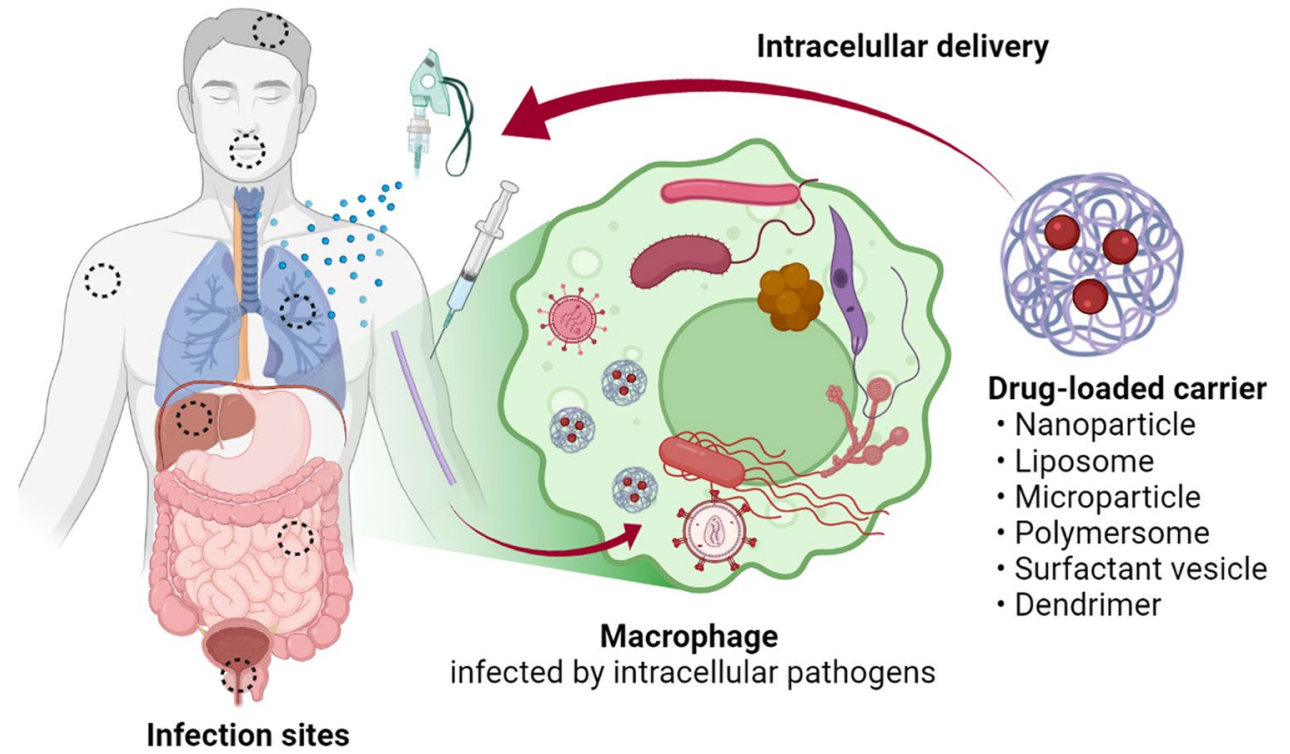


antimicrobial therapeutics against intracellular pathogens in vitro or in vivo. Here, antimicrobial therapeutics are defined broadly to include antiviral, antibacterial, antifungal, and antiparasitic agents. The initial database search strategies were prespecified as follows: search terms consisted of a combination of key words, (intracellular) in title/abstract AND (infection) in title/abstract AND (delivery) in title/ abstract; no publication date restrictions were applied; the search filter for language was set as "English." Reference lists of related research were additionally screened to identify eligible studies. Ethics committee review was waived as this study conducted by pooling existing data extracted from published primary research.

\section{Study Selection and Data Collection}

Those studies identified though initial search were screened for eligibility using the following inclusion criteria: (i) experimental data are provided to demonstrate the efficacy of intracellular delivery of antimicrobial therapeutics and/or their antimicrobial efficacy against intracellular pathogens in vitro or in vivo; (ii) carrier systems are used to deliver active drugs; (iii) sufficient raw data can be obtained from primary research. Review articles and duplicate studies were excluded from the meta-analysis. Studies that applied metals or microorganisms for preparation of intracellular delivery platforms were included. Study attributes, including the first author and year of publication, host cells, etiologic organisms, characteristics of carrier, types of materials (organic, inorganic, live cell derivative), active drug, intracellular delivery study methodology, in vitro and/or in vivo pharmacodynamic (PD) markers, antimicrobial efficacy results, and free drug control were extracted utilizing a predefined summary format. Authors resolved difference in opinion or study interpretation through discussion.

\section{Data Analysis and Statistical Methods}

The efficacy of intracellular carriers for antimicrobial therapeutics was evaluated qualitatively and quantitatively by pooling data from individual studies, and the results were presented with descriptive statistics. The parameters of intracellular delivery investigation assessed in this meta-analysis included what type of study methodologies were used for evaluation of intracellular delivery (microscopy, flow cytometry), whether in vitro and/or in vivo $\mathrm{PD}$ responses were evaluated, and whether the effects were compared against those of free drug counterparts. The primary in vitro PD markers investigated are: intracellular microbial burdens such as colony forming units (CFUs), viral plagues or titers, optical density, and microbial growth or inhibition rates; inhibitory concentrations including minimum inhibitory concentration (MIC), half maximal inhibitory concentration $\left(\mathrm{IC}_{50}\right)$, and half maximal effective concentration $\left(\mathrm{EC}_{50}\right)$. As for in vivo $\mathrm{PD}$ markers, survival rates and pathogen burden at specific times were assessed in animal models of related infection.

\section{Results}

\section{Selection of Relevant Original Studies}

The process of searching and identifying relevant studies is presented as Fig. 2. The initial search from PubMed and Embase yielded 1,891 citations and 67 additional articles were identified via reference lists in reviews of related research (14-17). Of those, 700 duplicates were excluded. Of the remaining 1,258 articles that underwent further screening of titles and abstracts, a total of 1,131 articles were excluded due to the reasons listed in Fig. 2. After full-text review, 28 additional articles were further removed, resulting in 99 studies satisfying the inclusion criteria for qualitative analysis: Bacterial 62 (62.6\%), viral $16(16.2 \%)$, fungal $8(8.1 \%)$, and parasitic $15(15.2 \%$; 2 articles on both bacterial and parasitic pathogens).

\section{Characteristics of Included Studies}

The yearly publication patterns of intracellular delivery of antimicrobial therapeutics show near-zero publications until the late 2000s and a sharp uptake in publication volume in the 2010s and thereafter (Fig. 3). The most commonly targeted intracellular pathogens were bacterial organisms throughout the study screening period, with the first study on Salmonella published in 1990 followed by scarce research until a sharp rise in publication volume in the late 2000s. None of the studies targeted parasitic, viral, or fungal intracellular pathogens until 2009, 2010, and 2015, respectively, with the first studied organism being Leishmania, Ebola, and Cryptococcus, respectively. The most dominant type of materials for delivery platforms was organic compounds, of which $54.5 \%$ of studies (54/99) employed synthetic polymers and 33.3\% (33/99) lipid particles (Fig. 4a). The most-commonly used carrier type was nanoparticles (in 51 out of 99 studies), followed by liposomes (in 15 out of 99 studies) (Fig. 4b). The particle size in the majority of studies $(63.6 \%)$ falls in the range of 100 to $<1000 \mathrm{~nm}$ (Fig. 4c). We have further analyzed the included studies by host cell types, carrier types, particle size ranges, and administration routes. Detailed results are summarized in Tables $\mathrm{S} 1$ to $\mathrm{S} 8$ in supplementary materials. 
Fig. 2 Study selection flow diagram

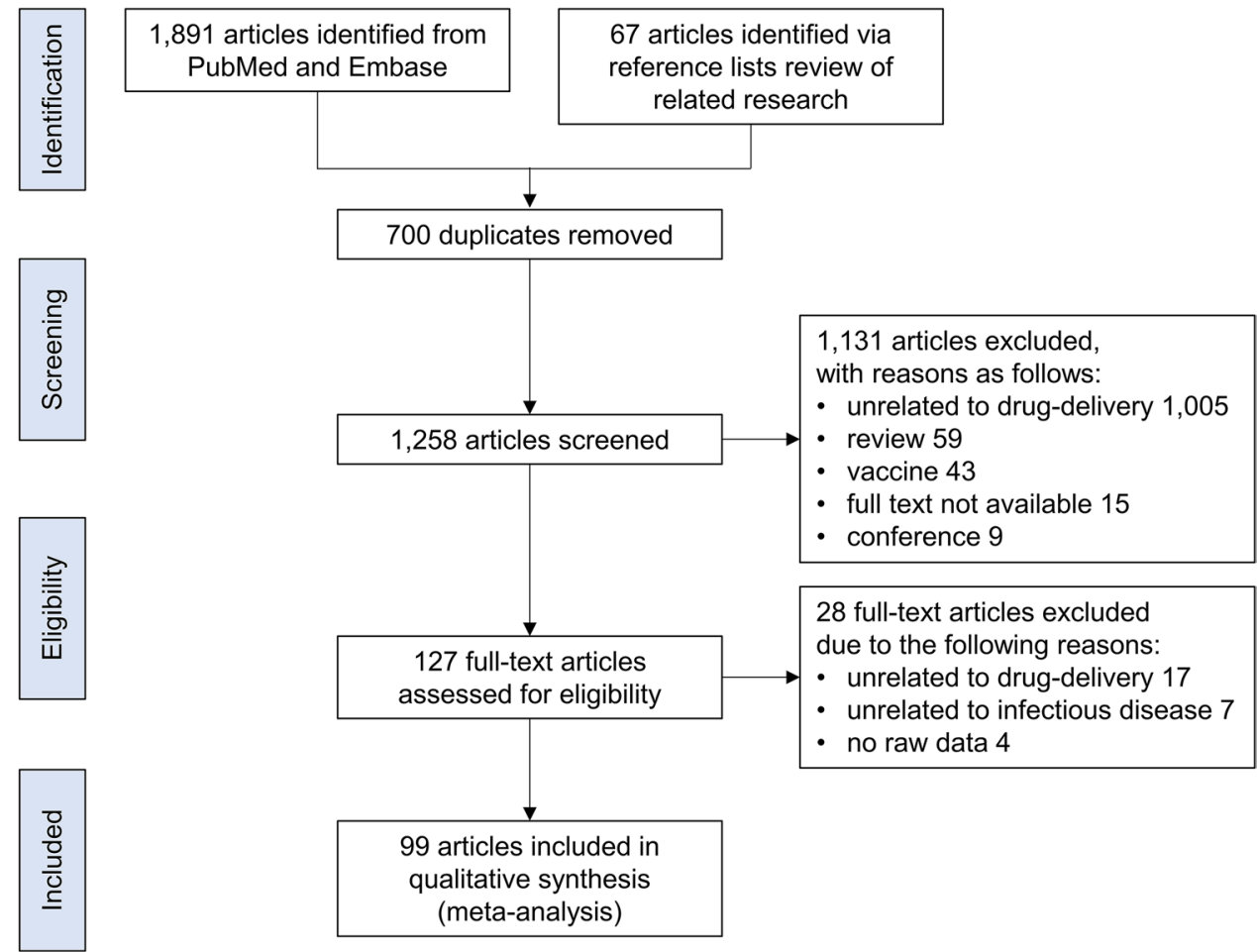

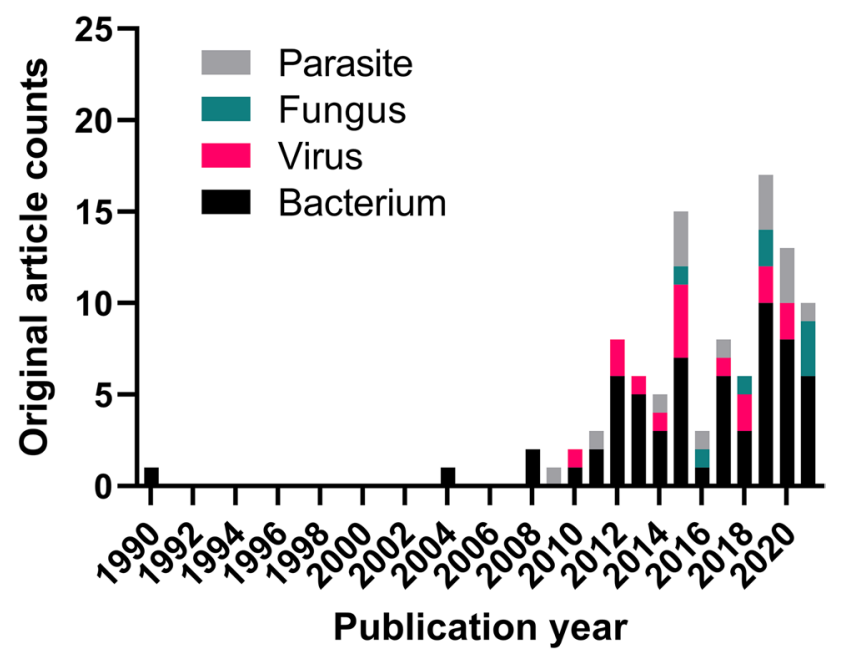

Fig. 3 Publication trends of the literature focusing on drug delivery systems for the treatment of intracellular infections, subdivided by etiologic organisms

\section{Bacterial Intracellular Pathogens}

The 62 eligible studies on bacterial intracellular pathogens are summarized in Table I. The most commonly studied intracellular bacteria were Staphylococcus aureus $(\mathrm{n}=20)$, followed by Mycobacterium tuberculosis $(\mathrm{n}=17)$ and Salmonella $(\mathrm{n}=9)$ (Fig. 5). There were two studies by Lueth (2019) (18) and by Omolo (2021) (19), which provided the most comprehensive data supporting intracellular delivery and antimicrobial efficacy of drug-loaded carriers both in

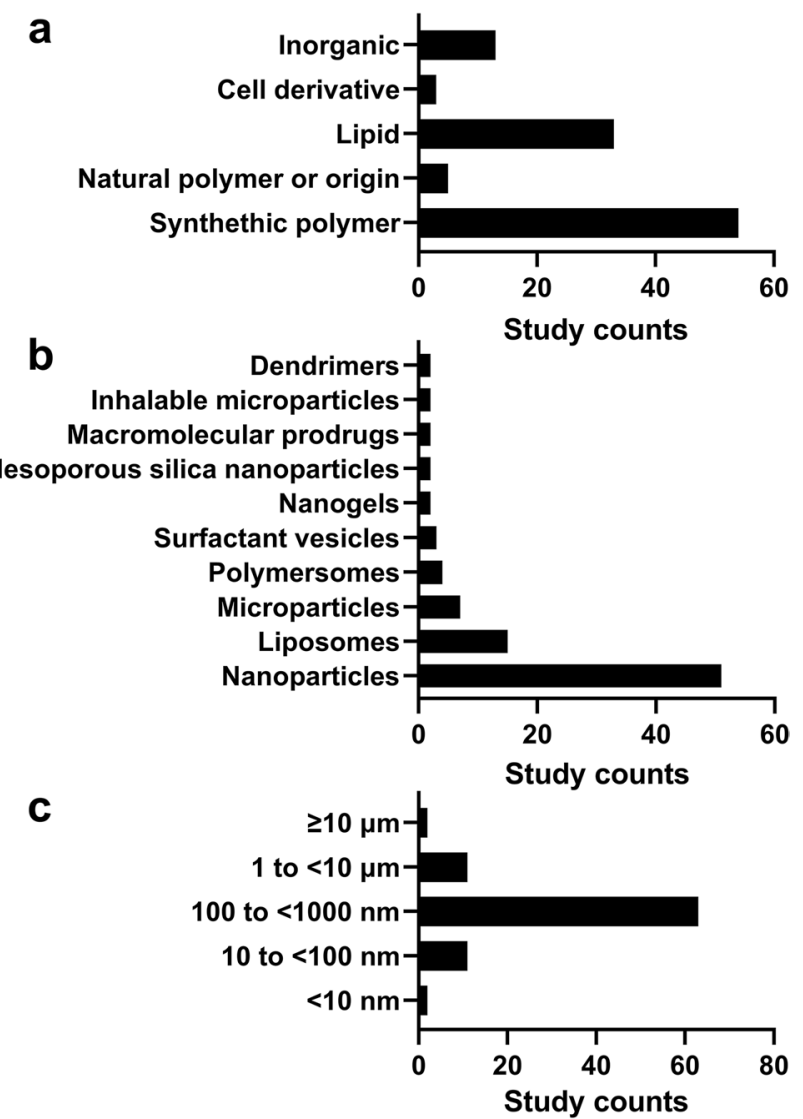

Fig. 4 Drug carriers used for intracellular delivery of antimicrobials by (a) material types, (b) formulation types, and (c) particle sizes 


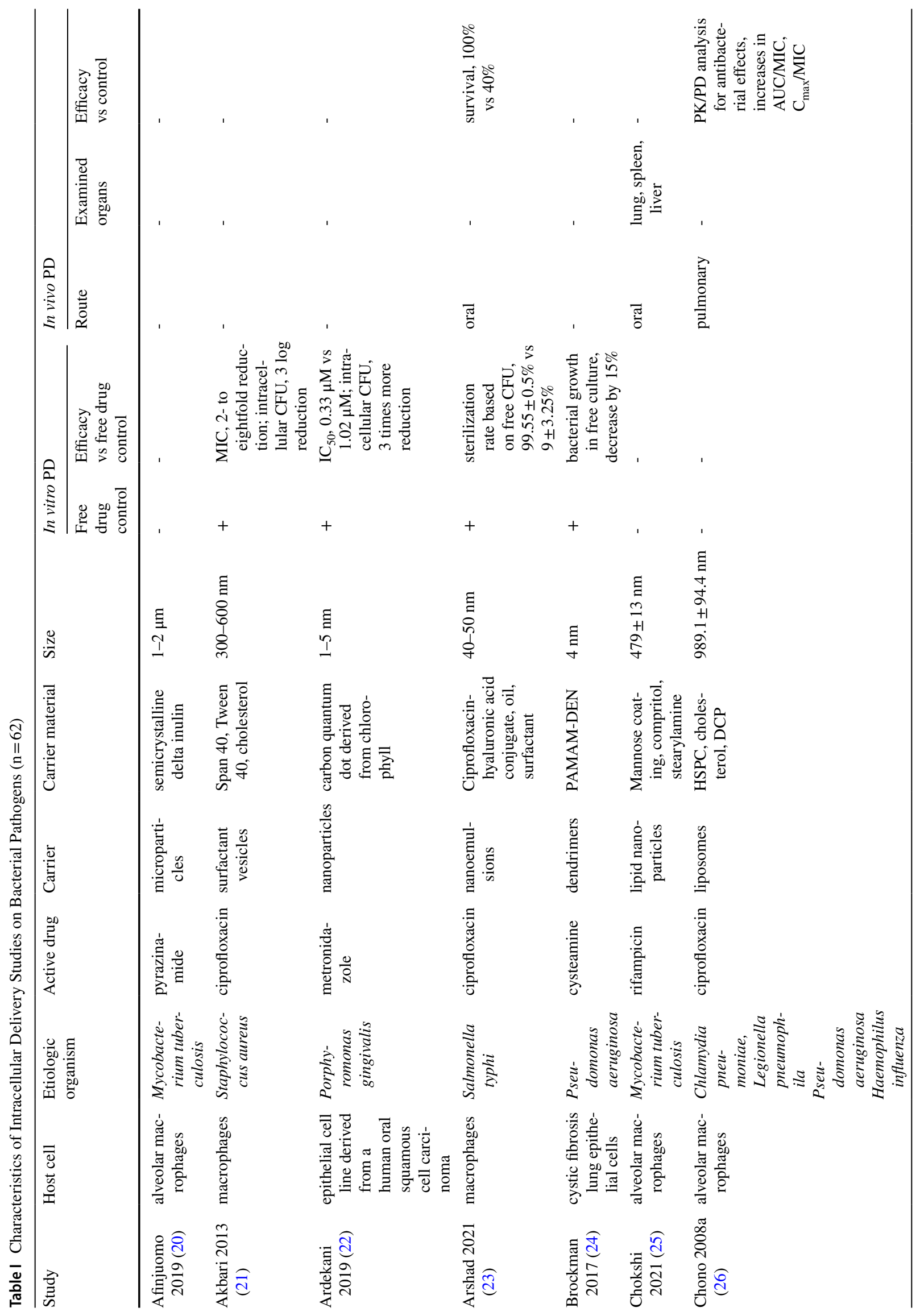




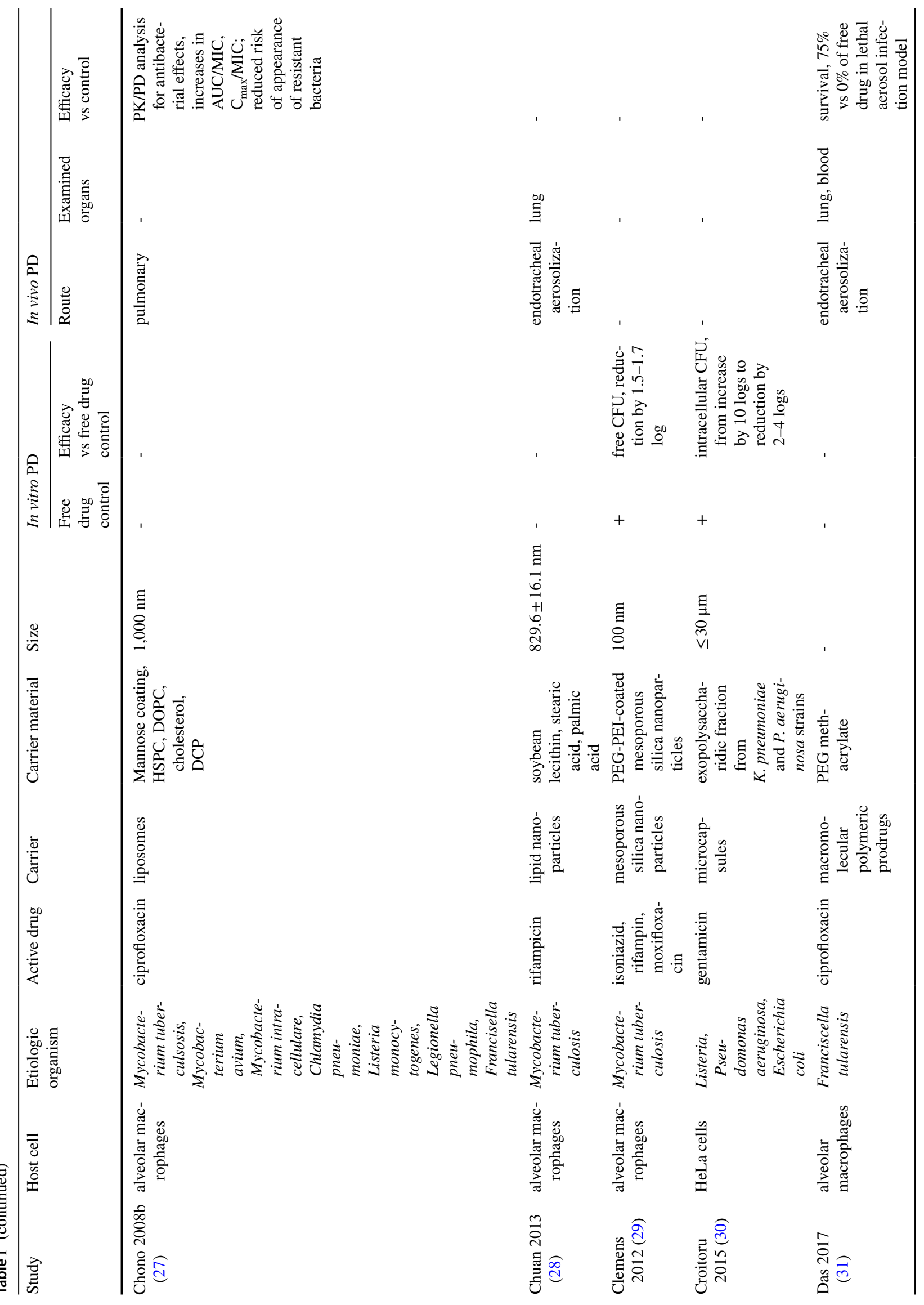




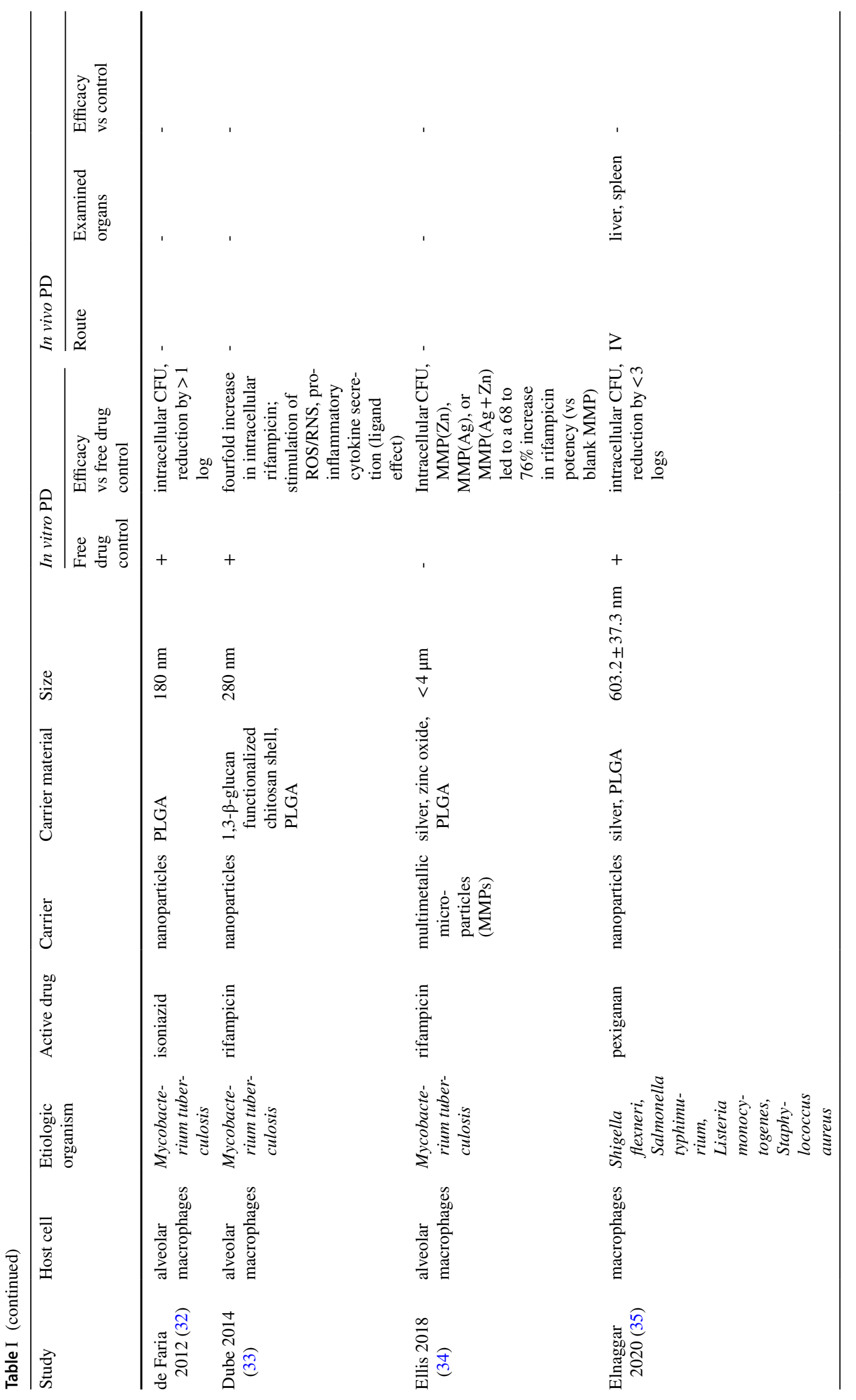




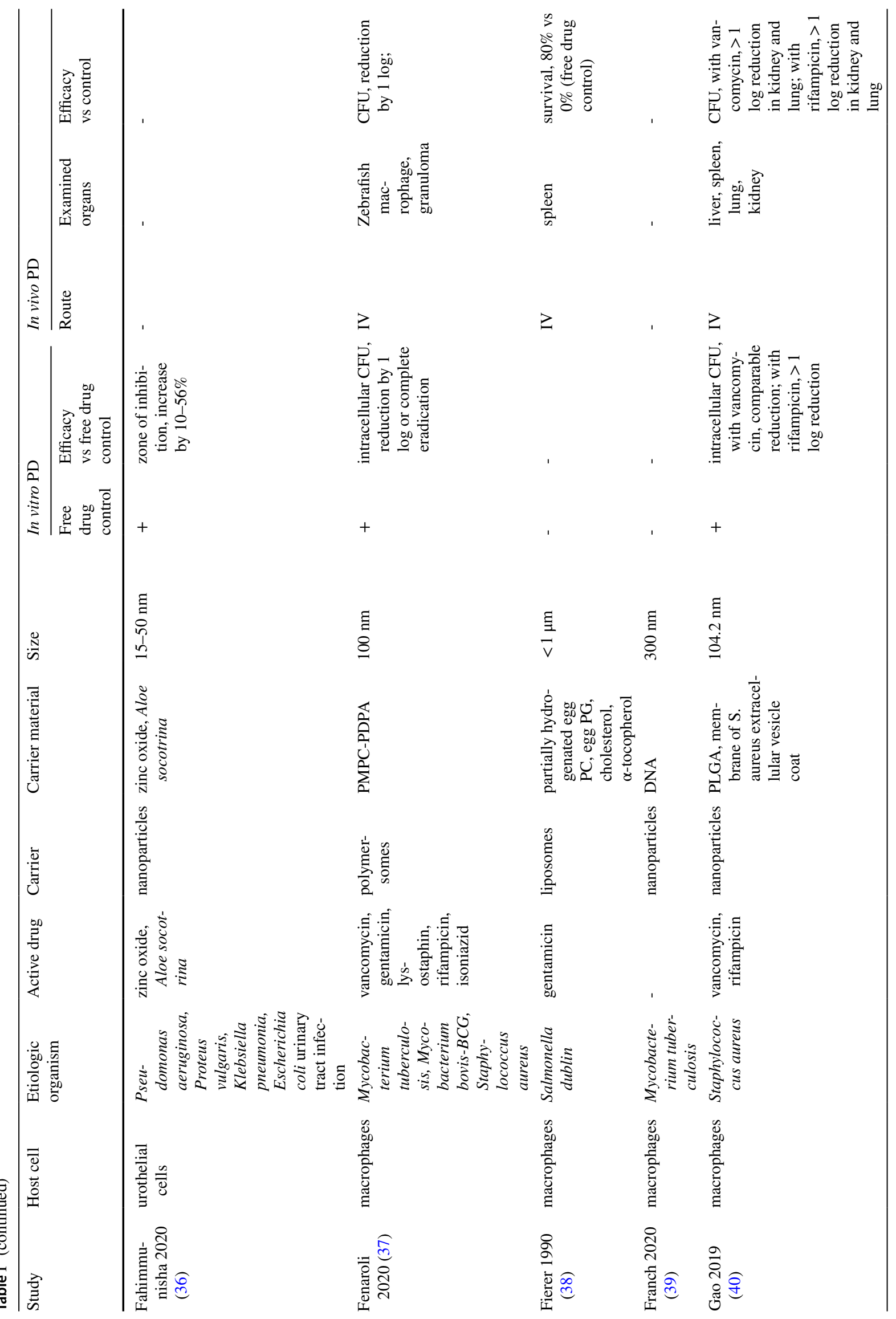




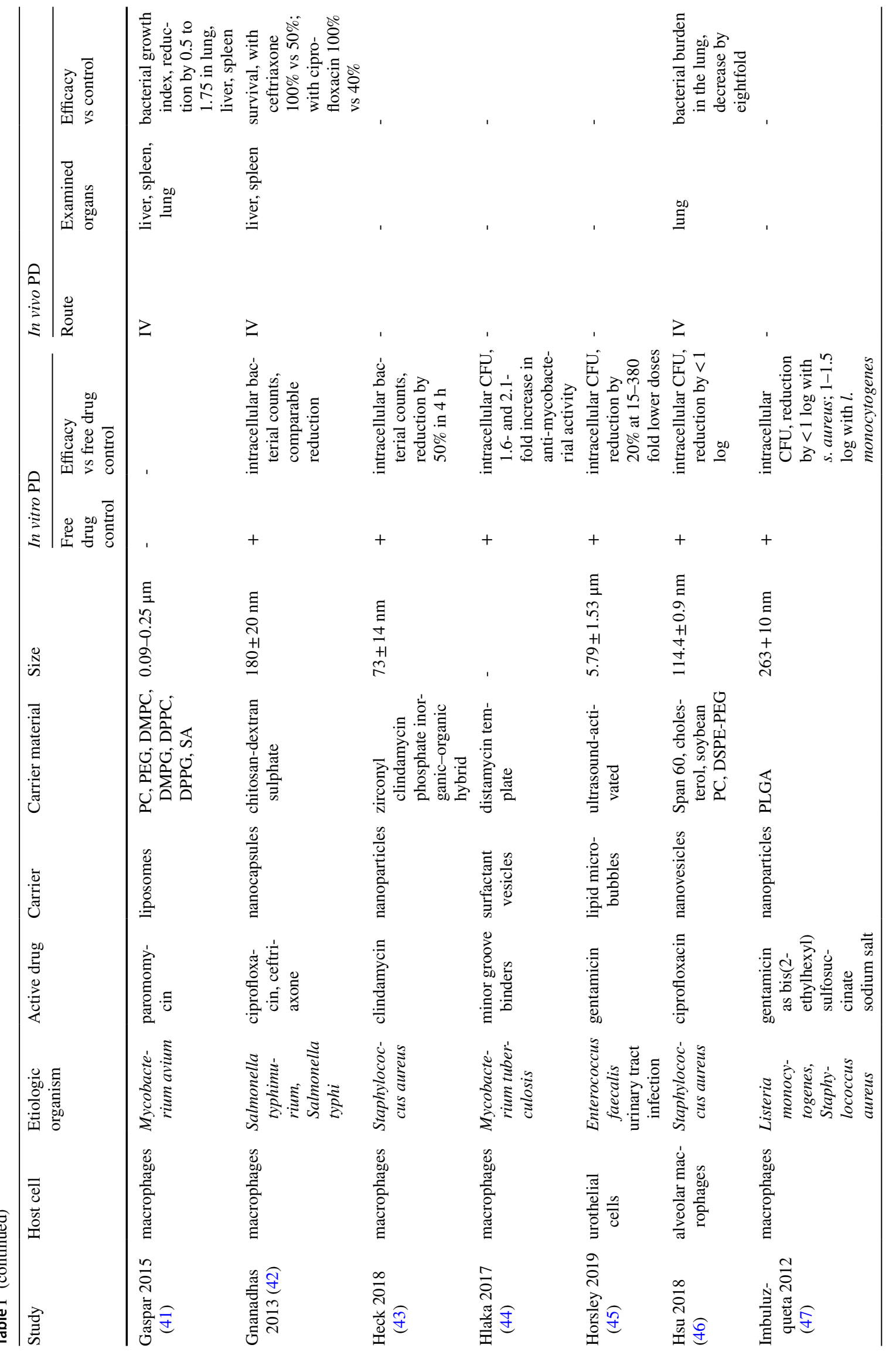




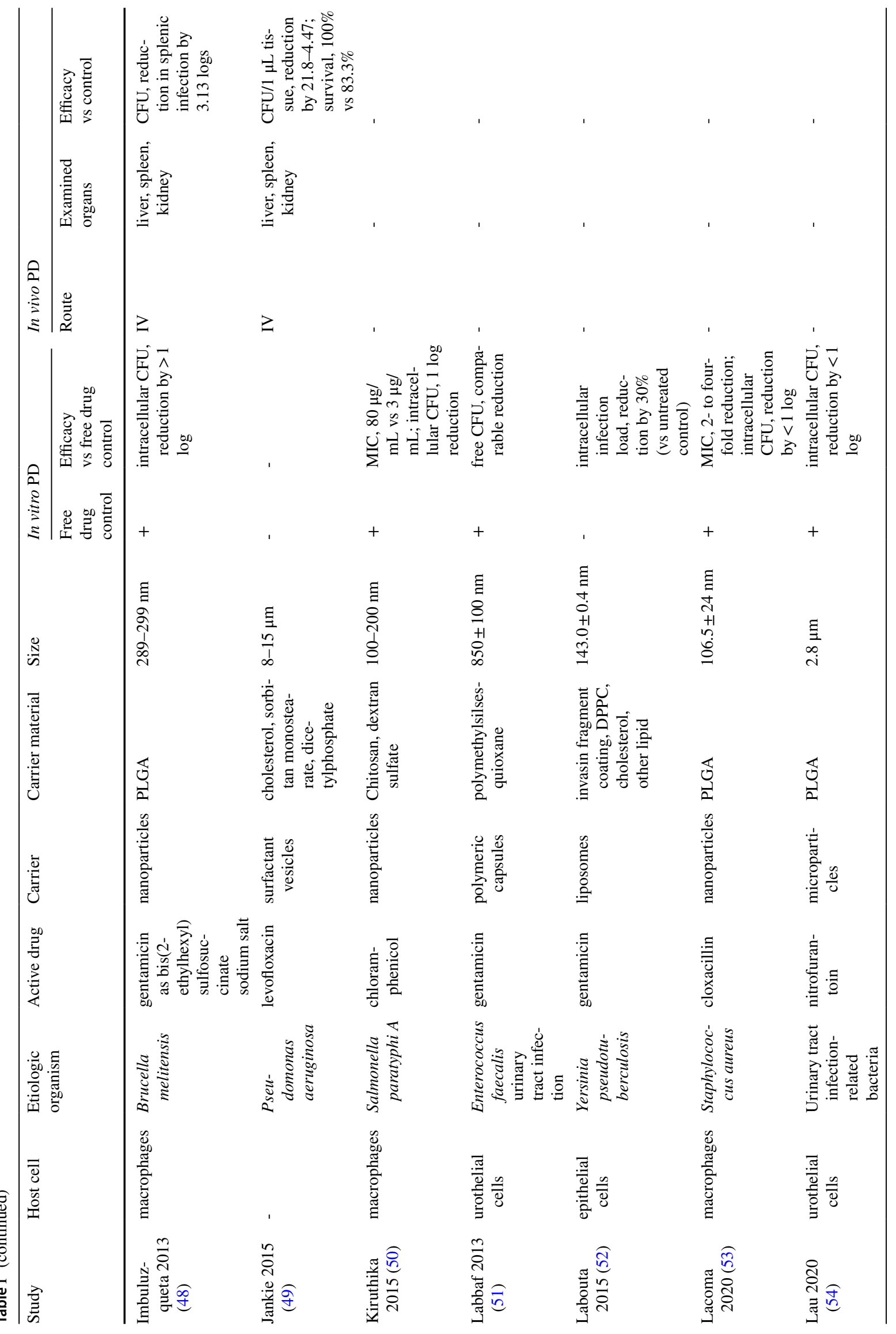




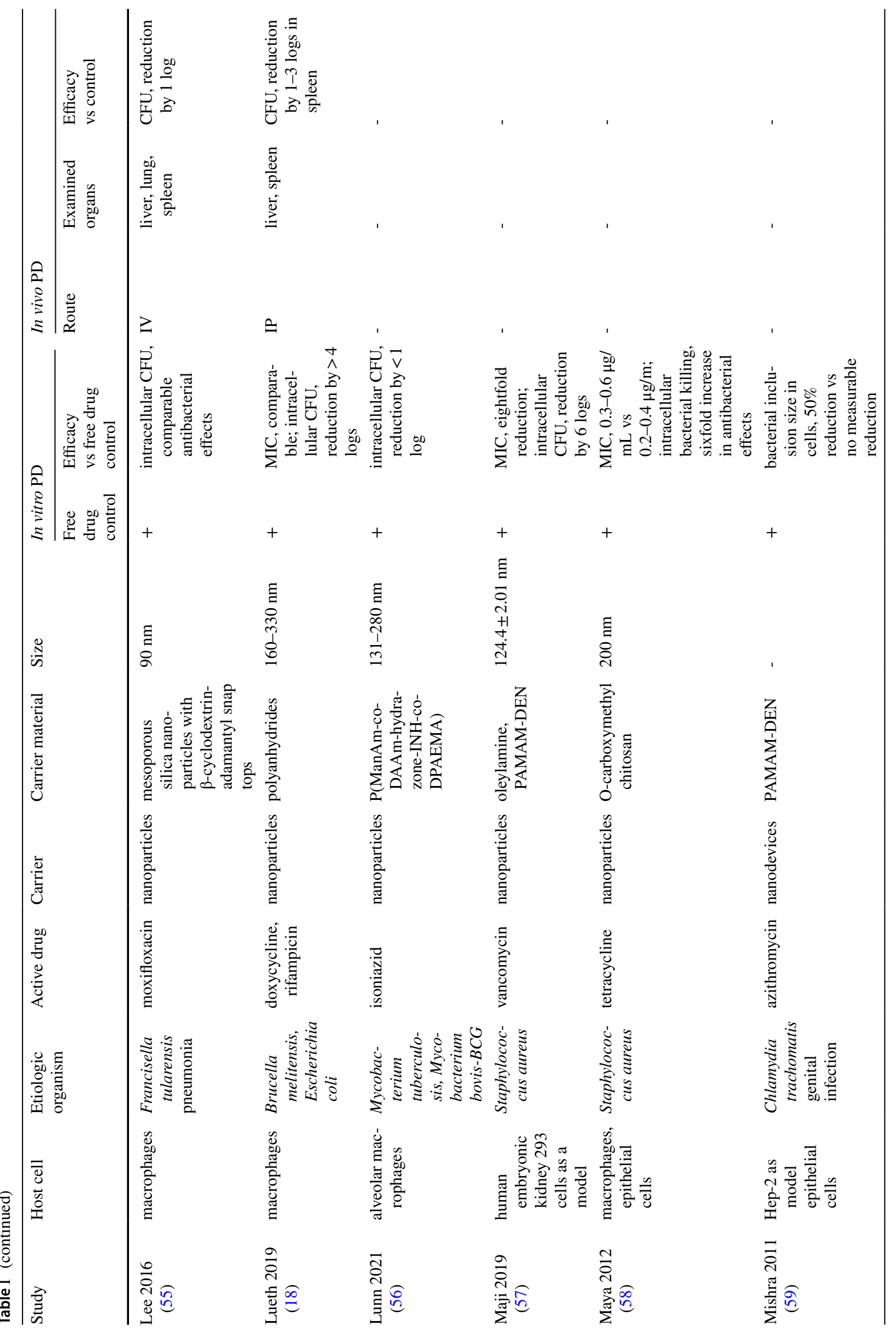




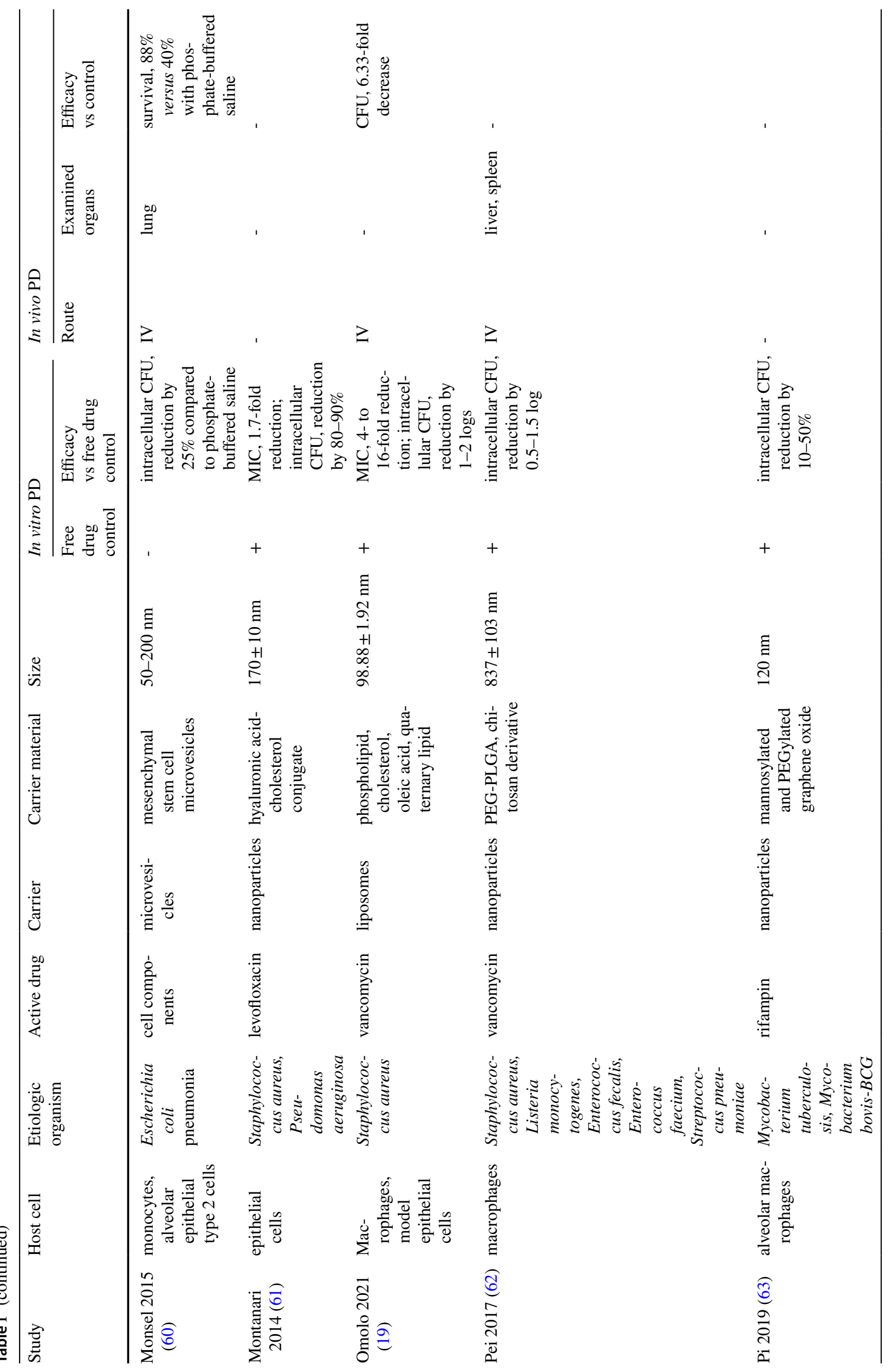




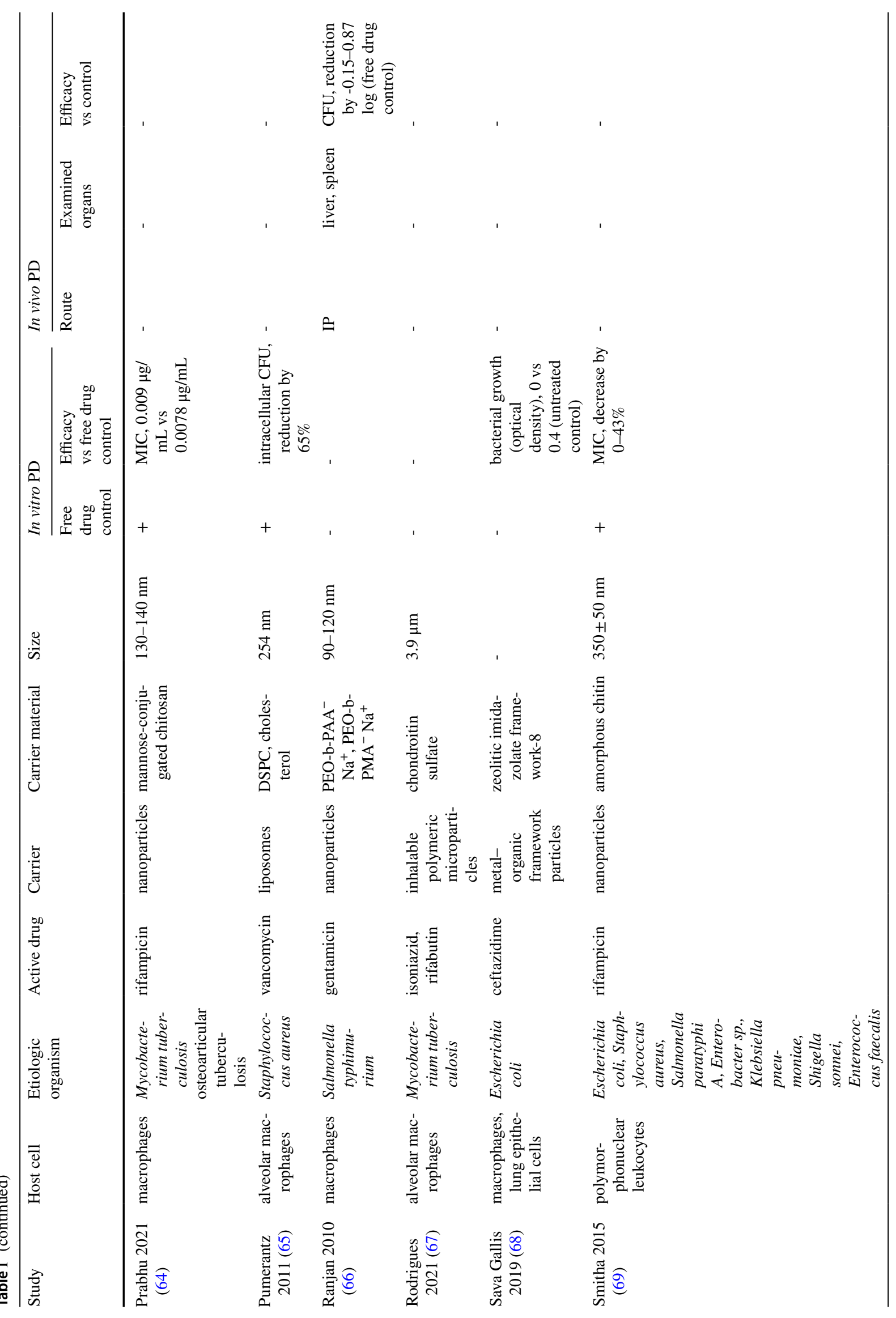




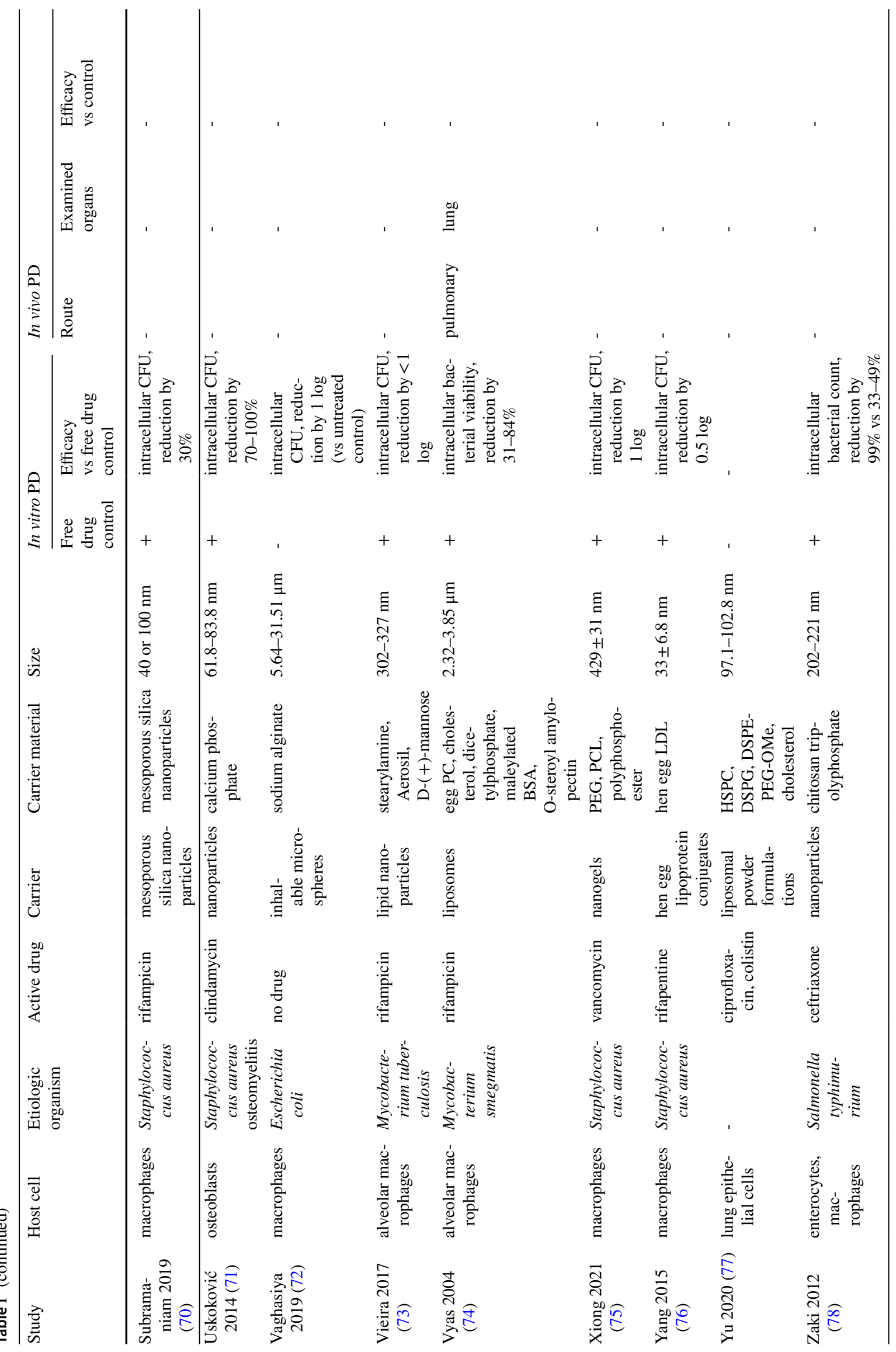




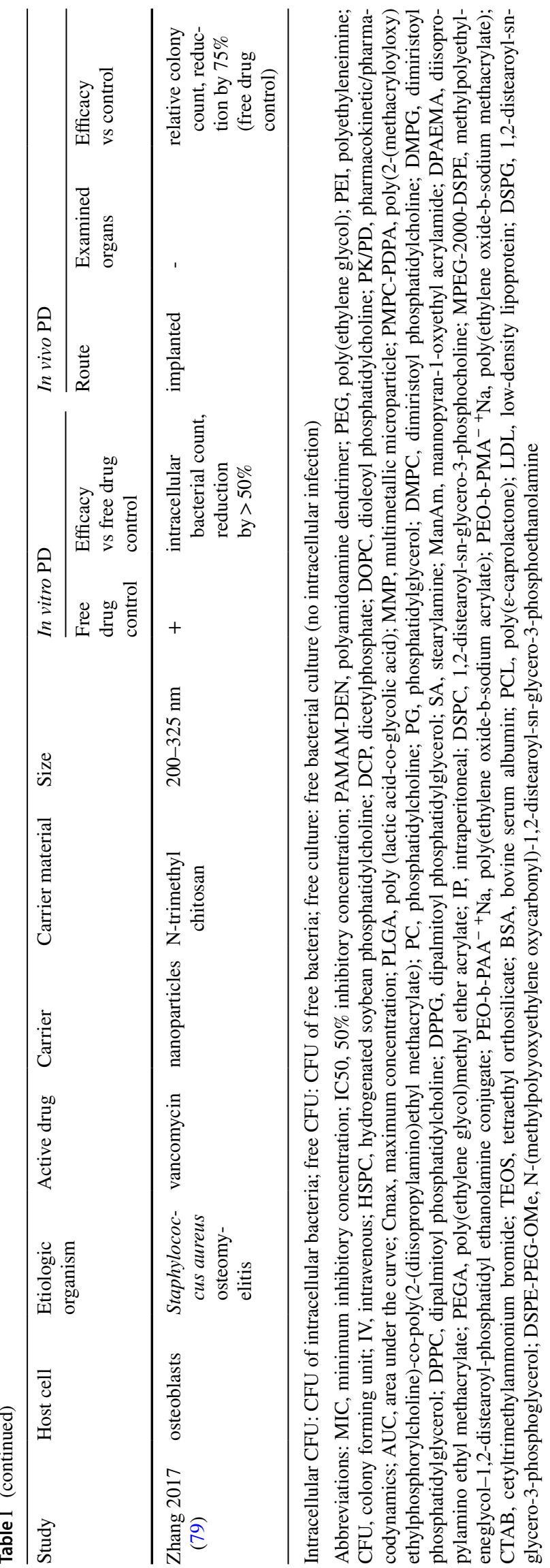

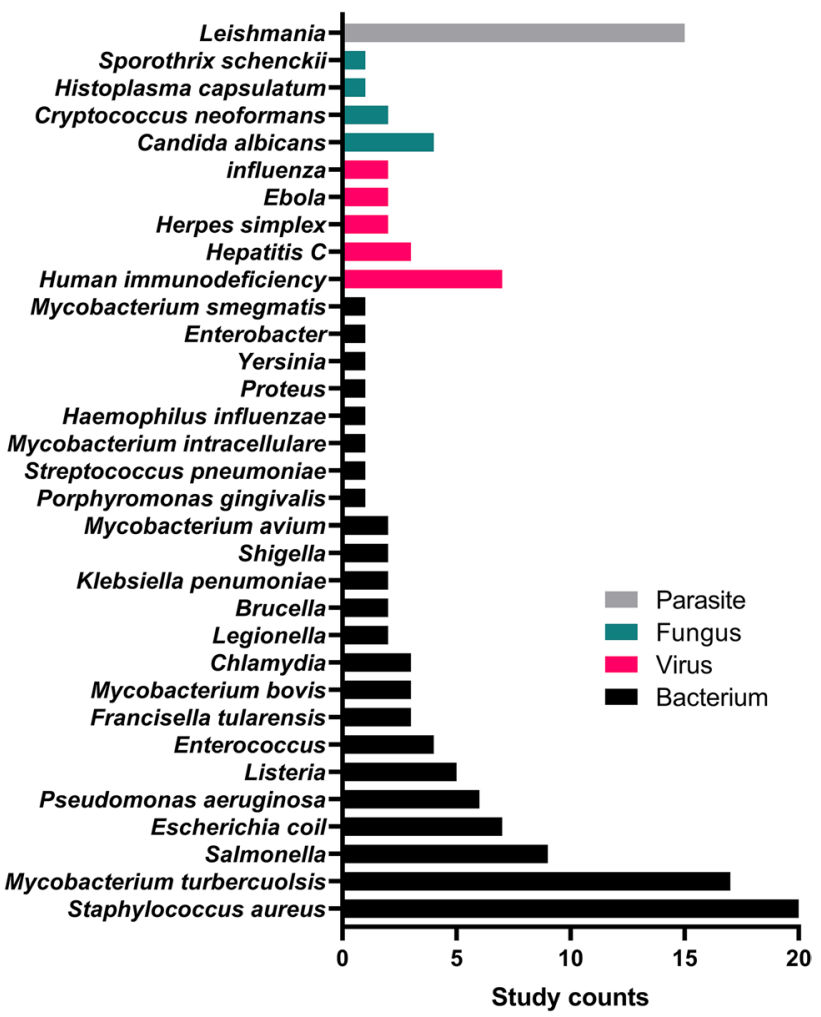

Fig. 5 Commonly studied intracellular pathogens

vitro and in vivo. In the former, a polymer-based nanoparticle was developed to encapsulate doxycycline and rifampicin to eradicate Brucella melitensis or Escherichia coli (18). Intracellular delivery was confirmed by microscopic imaging. In the latter, $\mathrm{pH}$-responsive liposomes were produced to load vancomycin to kill methicillin-resistant Staphylococcus aureus (MRSA) (19). Here, intracellular delivery was confirmed by flow cytometry. In both studies, antibacterial activity (changes in MIC and CFU of intracellular bacteria) was compared against those of a free drug control in vitro, where the encapsulated drug showed more efficient bacterial killing than the free drug counterpart. The in vitro results were further validated in mouse models of systemic or topical bacterial infection (CFU changes). The distribution of particles in the main organs of interest (liver and spleen) were determined only in the former study.

\section{Viral Intracellular Pathogens}

Table II summarizes the 16 intracellular delivery studies of antimicrobial therapeutics targeting viral pathogens. The most commonly studied intracellular viruses were human immunodeficiency virus $(\mathrm{n}=7)$, followed by hepatitis $C$ virus $(\mathrm{n}=3)$ (Fig. 5). A 2018 study by Hu et al. (80) showed the most comprehensive data for intracellular delivery of diphyllin or bafilomycin and their antimicrobial efficacy. The drug was encapsulated in nanoparticles prepared with 


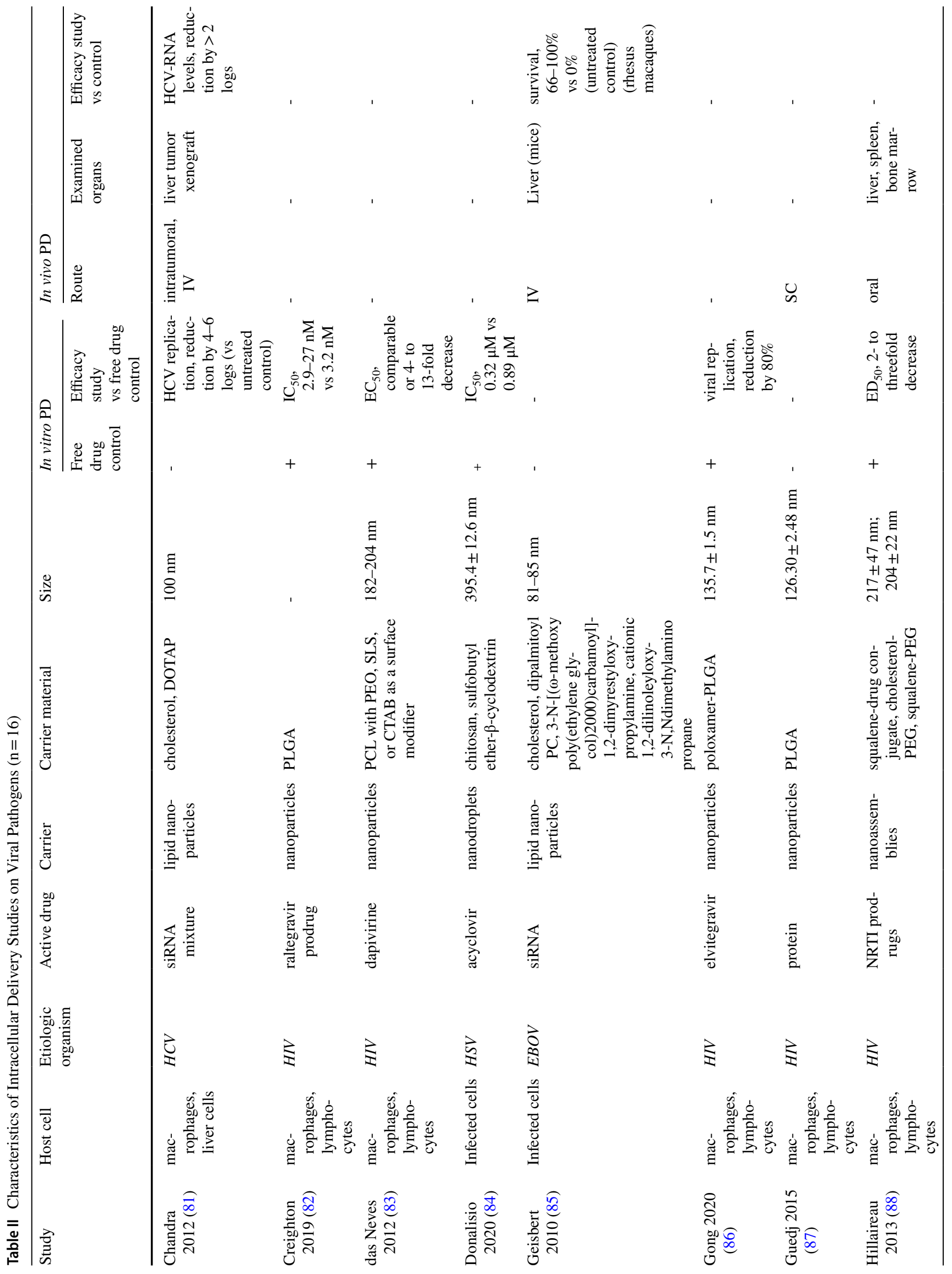




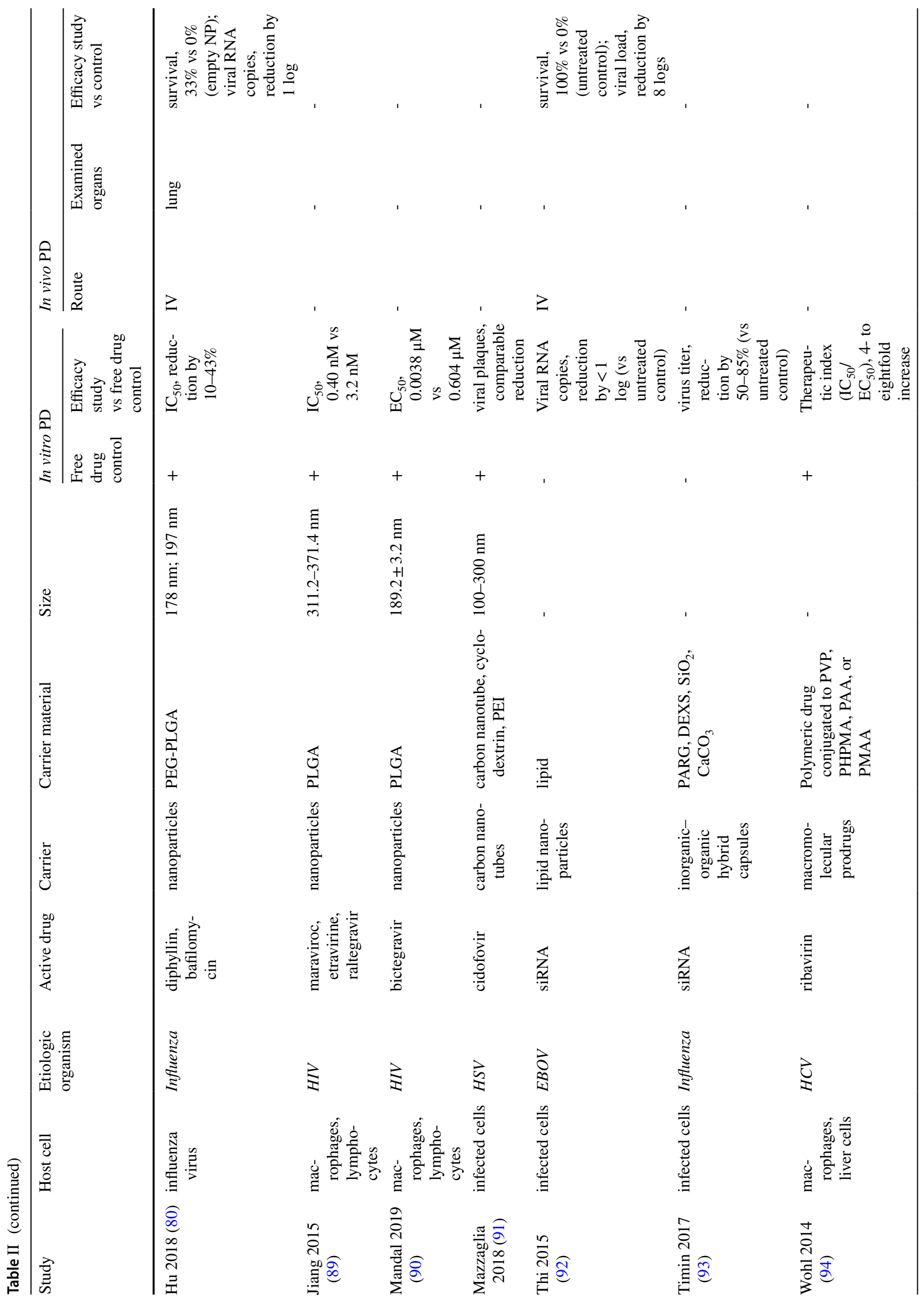




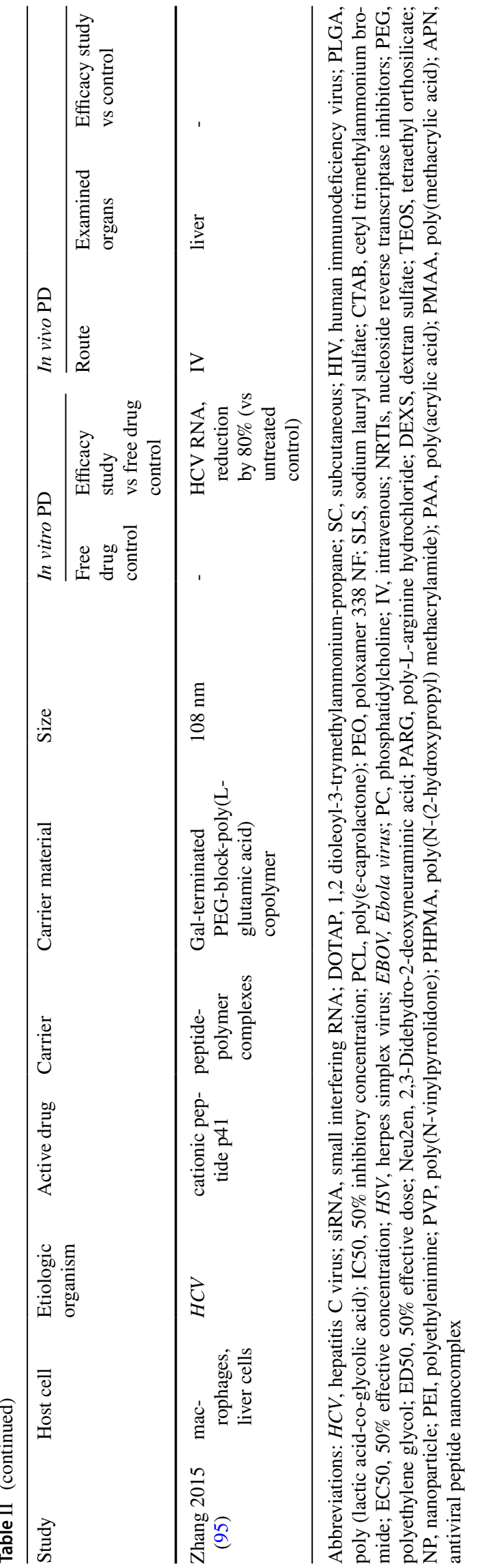

poly(ethylene glycol)-block-poly(lactide-co-glycolide) (PEG-PLGA) copolymers. Intracellular delivery of the nanoparticles was confirmed microscopically. For in vitro antiviral effects against influenza virus, $\mathrm{IC}_{50}$ and viral titers were compared with those of free drug controls. In an in vivo mouse model of influenza infection, survival rates and viral RNA copies were measured as PD markers. The delivery of intravenously injected particles to the lungs, the organ of interest, was demonstrated based on the reduction of viral loads, but nanoparticle distribution in other organs was not examined.

\section{Fungal Intracellular Pathogens}

The 8 studies on fungal intracellular infection are summarized in Table III. The most commonly studied intracellular fungi were Candida albicans $(n=4)$ (Fig. 5). In an exemplary study by Batista-Duharte (96), a needle-like lipid assembly was prepared to deliver amphotericin B intracellularly to kill Sporothrix schenckii. Microscopic imaging data were provided to confirm intracellular delivery. The in vitro antifungal activity, in terms of CFU and MIC changes, of the carrier-mediated delivery was superior to that of a free drug. The antifungal effects were validated in a mouse model of systemic fungal infection with CFUs as a PD marker. The liver and spleen of the treated animals were examined to evaluate the fungal load.

\section{Parasitic Intracellular Pathogens}

Table IV summarizes the 15 intracellular drug delivery studies targeting parasitic pathogens. Here, all studies chose Leishmania species as their target pathogen (Fig. 5). Three studies (104-106) incorporated the most comprehensive supporting data. Intracellular delivery of particles was confirmed by microscopy and flow cytometry in all three studies. In vitro killing effects (parasitic burden and $\mathrm{IC}_{50}$ changes) were compared with those of free drug controls. All three studies demonstrated enhanced in vivo parasite inhibition effects of the carrier-mediated delivery versus a free drug. The biodistribution of intravenously injected carrier particles was investigated in two studies, based on drugs delivered to major organs, showing that the liver and spleen were common targets $(104,105)$.

\section{Study Methodologies: Intracellular Delivery and Antimicrobial Efficacy}

We investigated how intracellular drug delivery was evaluated in each study: imaging and flow cytometric analysis of labeled carriers, in vitro PD (e.g., killing of intracellular bacteria or counting viral plaques), or in vivo $\mathrm{PD}$. Table $\mathrm{V}$ summarizes study methodologies employed in the analyzed 
studies. Due to the lack of common readouts and the nonlinear relationship of dye concentration versus fluorescence intensity, it was difficult to compare the studies with respect to the intracellular delivery efficiencies of different carriers. As for the intracellular delivery of carriers, 73.7\% (73/99) and $37.4 \%$ (37/99) of studies performed microscopy and flow cytometry, respectively, and $78.8 \%$ (78/99) of them incorporated either of the two methodologies. Twenty-one out of $99(21.2 \%)$ performed neither study to support the intracellular delivery. For the antimicrobial efficacy, $80.8 \%$ (80/99) of studies investigated differential effects of drugloaded carriers on in vitro PD markers as compared to either untreated, empty carrier, or free drug controls. Of those, $69.7 \%$ (69/99) of studies compared antimicrobial effects against a free drug control, utilizing either microbial burdens (55/99) or inhibitory concentrations $(31 / 99)$ or both (17/99) as PD markers. Thirty-three out of 99 (33.3\%) studies conducted in vivo PD studies with pathogen burdens or survival as readouts. Eight studies (8.1\%) did not show any evidence of intracellular delivery of antimicrobial therapeutics (no microscopic imaging, no flow cytometry, and no in vitro PD study).

\section{Discussion}

Intracellular pathogens have evolved to counterbalance the host immunity to survive or multiplicate within macrophages, otherwise hostile environments. In order to treat intracellular infections, it is important to develop an effective intracellular delivery system that helps antimicrobial therapeutics to enter the infected cells, traffic in the cells to the desired intracellular niche harboring pathogens, and kill the pathogens in a timely manner. In this meta-analysis, we performed a descriptive and qualitative evaluation of the studies focused on carrier development for the intracellular delivery of antimicrobial agents. Unlike drug delivery studies in the cancer arena, most intracellular pathogens-targeting studies do not report intracellular drug concentrations, percentage injected dose (\%ID) or $\mathrm{mg} / \mathrm{kg}$ from infected cells or target organs following drug administration. Therefore, not enough raw data were available to perform physiological and pharmacokinetic model-based analyses. Of all the bacterial, viral, fungal, and parasitic intracellular pathogens, bacteria were the most common microbes studied, with Staphylococcus aureus and Mycobacterium tuberculosis being the top two etiologic organisms. They are well known for their ability to acquire antibiotic resistance, and one of the mechanisms behind the resistance is to parasitize macrophages. Notably, Leishmania were the sole species that were chosen as a target pathogen in the parasite category. Leishmaniasis is one of the deadliest infections caused by the obligate intracellular protozoa, by which more than 1.5 million people are newly affected and about 70,000 deaths occur each year (117). It can be transmitted via sand flies, and about 70 animals including humans are known hosts of Leishmania (118). There are other protozoan parasites, such as Toxoplasma gondii and Trypanosoma cruzi, which take advantage of phagocytes to grow, replicate, and evade the host immune system. However, Leishmania species differ from other protozoan parasites in that they predominantly exploit macrophages as host cells (119). Pentavalent antimonial compounds, for example meglumine antimoniate, are the mainstay of treatment but with severe side effects, such as hepatotoxicity and cardiotoxicity (120). Due to the severity of the disease and many challenges that it poses against mammalian populations, there have been a steady and increasing number of studies targeting Leishmania.

Our analysis shows that seventy-four (74.7\%) out of 99 studies are done with macrophages (Table S1). The predominance of macrophages as the host cells is attributed to their role in innate immunity as the first defense to the invading bacteria (121). The most common administration route used in in vivo PD studies was intravenous injection (in 25 (58.1\%) out of 43 studies) (Table S5). Upon administration, drug-loaded nanocarriers undergo opsonization, distribution in the reticuloendothelial system (RES) organs, and subsequent phagocytic uptake predominantly by macrophages. The particle size in the majority of studies (63.6\%) falls in the range of 100 to $<1000 \mathrm{~nm}$ (Fig. 4c, Table S3), which is likely driven by the administration route (intravenous injection) and biodistribution in the RES organs where the most infected phagocytes are located $(14,35)$. The most commonly used carrier type was nanoparticles followed by liposomes, in $51(51.5 \%)$ and $15(15.2 \%)$ out of 99 studies, respectively (Fig. 4b, Table S7), some of which contained mannose or $\beta$-glucan ligands to target receptors (e.g., CD206 or Dectin 1) expressed on macrophages.

Most studies (78.8\%) provided some proof of intracellular delivery based on microscopic imaging of labeled carriers in the cells or flow cytometric quantitation of cellular fluorescence after incubation with the carriers, but not to the organelle levels: how the carriers traffic in the cells and escape endosomes to finally reach the intracellular niche where the pathogens are hiding. We found that only 31 out of 99 studies provided comparative inhibitory concentrations $\left(\mathrm{MIC}, \mathrm{IC}_{50}\right.$, or $\mathrm{EC}_{50}$ ) against a free drug control. There were 8 studies that claimed their carrier system was for intracellular delivery of antimicrobial therapeutics but did not provide any experimental evidence supporting such claims, such as microscopic imaging, flow cytometry, and in vitro PD.

While microscopy and flow cytometry are dominant tools to investigate intracellular delivery of carriers, the following limitations need to be considered in interpreting the results. To enable microscopic or flow cytometric detection of carriers, fluorescent dyes are incorporated in the carriers by 


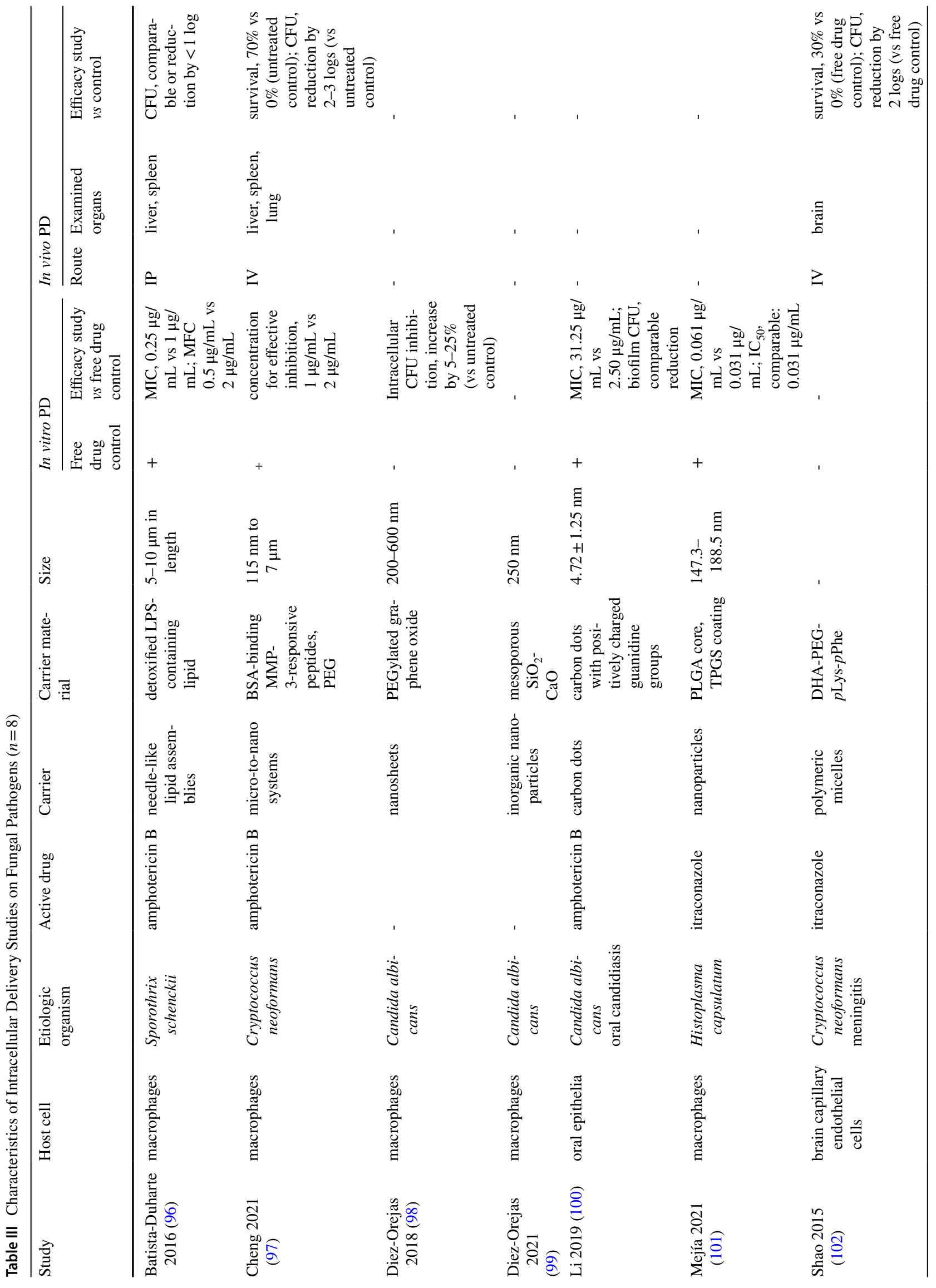




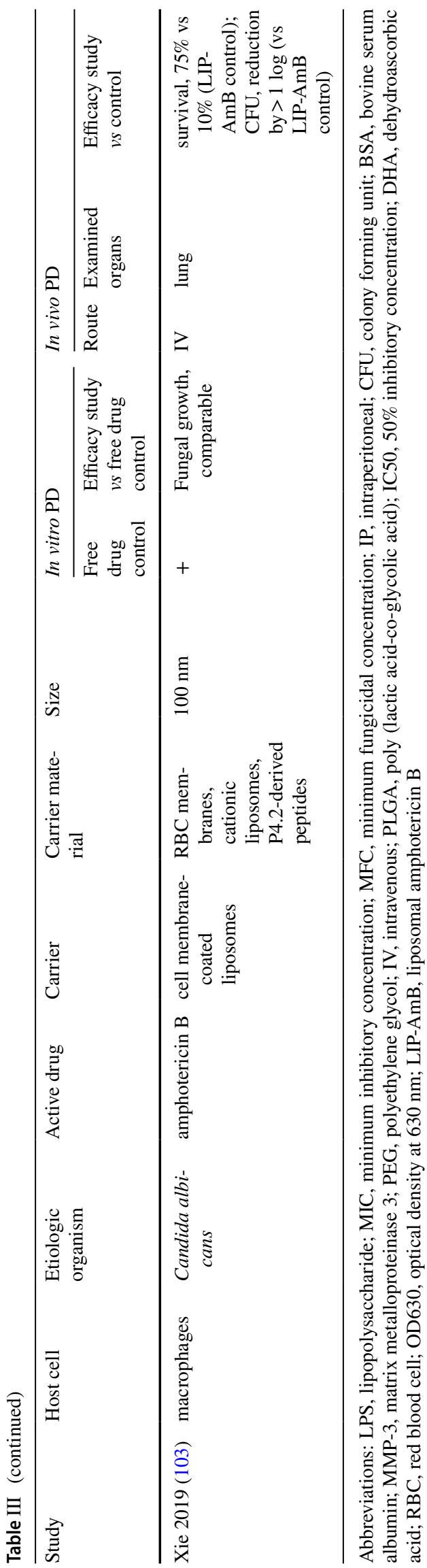

chemical conjugation or physical encapsulation (122). In the former, the fluorescent signals indicate the carriers (provided that the conjugation is stable throughout the experiment). In the latter, the fluorescent dye is considered a proxy of the delivered drug. Both cases have caveats. It is often assumed that the intracellular delivery of a carrier is synonymous to intracellular delivery of a drug. It is not always the case if the drug is prematurely released before the carrier enters the cells. Drug release profile measured in buffered saline does not warrant stable drug encapsulation since serum proteins can accelerate the drug release (123); therefore, one may not exclude the possibility of premature drug release in vivo on the basis of in vitro release kinetics. On the other hand, when a dye is physically encapsulated in the delivery platform, intracellular fluorescent signal only indicates that the dye can be delivered or released into the cell. While this result may provide a reasonable anticipation that a drug may be able to enter the cells likewise, it cannot be taken for granted since the dye does not always represent physical and chemical properties of the therapeutic agents. Moreover, some of the lipophilic dyes may leach out of carriers and partition to the cell membrane upon the carrier-to-membrane contact, without the carrier entering the cells (122). In this case, the fluorescence-based methods can produce a misleading conclusion about the carrier. Therefore, the results from both methods may not be used as sole evidence for intracellular delivery of drugs. If these methods indicate intracellular delivery of carriers and drug surrogates, additional studies need to be performed with drug-loaded carriers to confirm the intracellular delivery of a drug. For example, drug concentration can be measured in vitro after treating the cells with the drug-loaded carriers. Nevertheless, the entry of drug into cells via the designed carrier does not warrant intracellular trafficking to the target organelles such as endoplasmic reticulum-like vacuoles, late endosomal compartments, and macrophage phagosomes. Therefore, it is preferable to complement with in vitro PD tests, such as intracellular CFU.

To understand the contribution of carriers to intracellular delivery of a drug, control groups need to be selected carefully. When we surveyed the published reports, $69.7 \%$ have compared the in vitro antimicrobial efficacy of encapsulated therapeutic agents to the free control. Of these, only $31.3 \%$ provided comparative $\mathrm{MIC}, \mathrm{IC}_{50}$, or $\mathrm{EC}_{50}$ versus that of the free drug control. Given the potential bioactivity of carriers, it is desirable to include a drug-free carrier and a mixture of drug and drug-free carrier as additional controls. For example, chitosan or fucoidan, one of the commonly used carrier materials, have shown to induce antibacterial activity (124, 125). Without a comparison with an unformulated drug, drug-free carrier, and their mixture, it is difficult to determine whether the enhanced therapeutic efficacy of a carrierloaded drug is due to the encapsulation and intracellular 


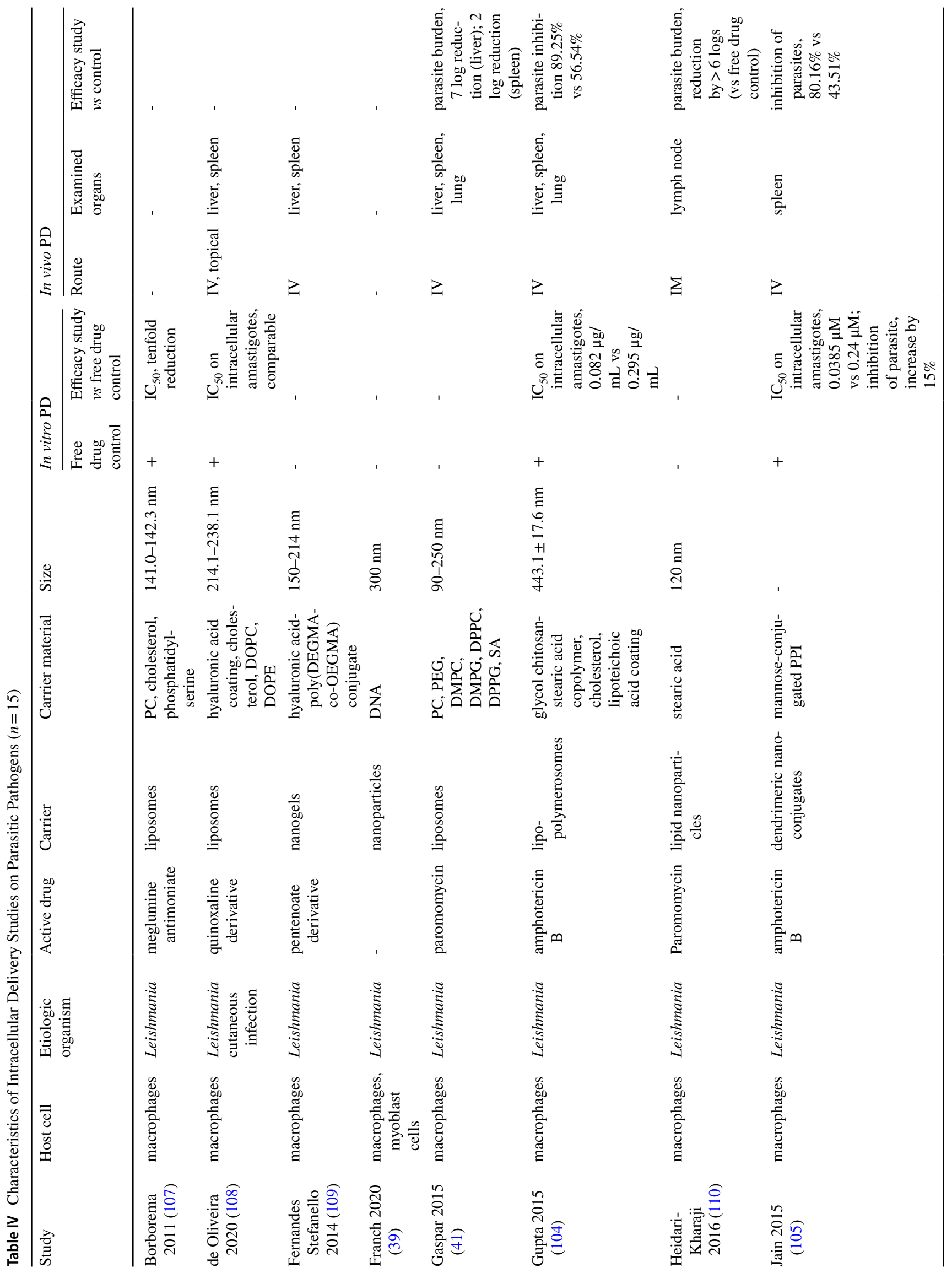




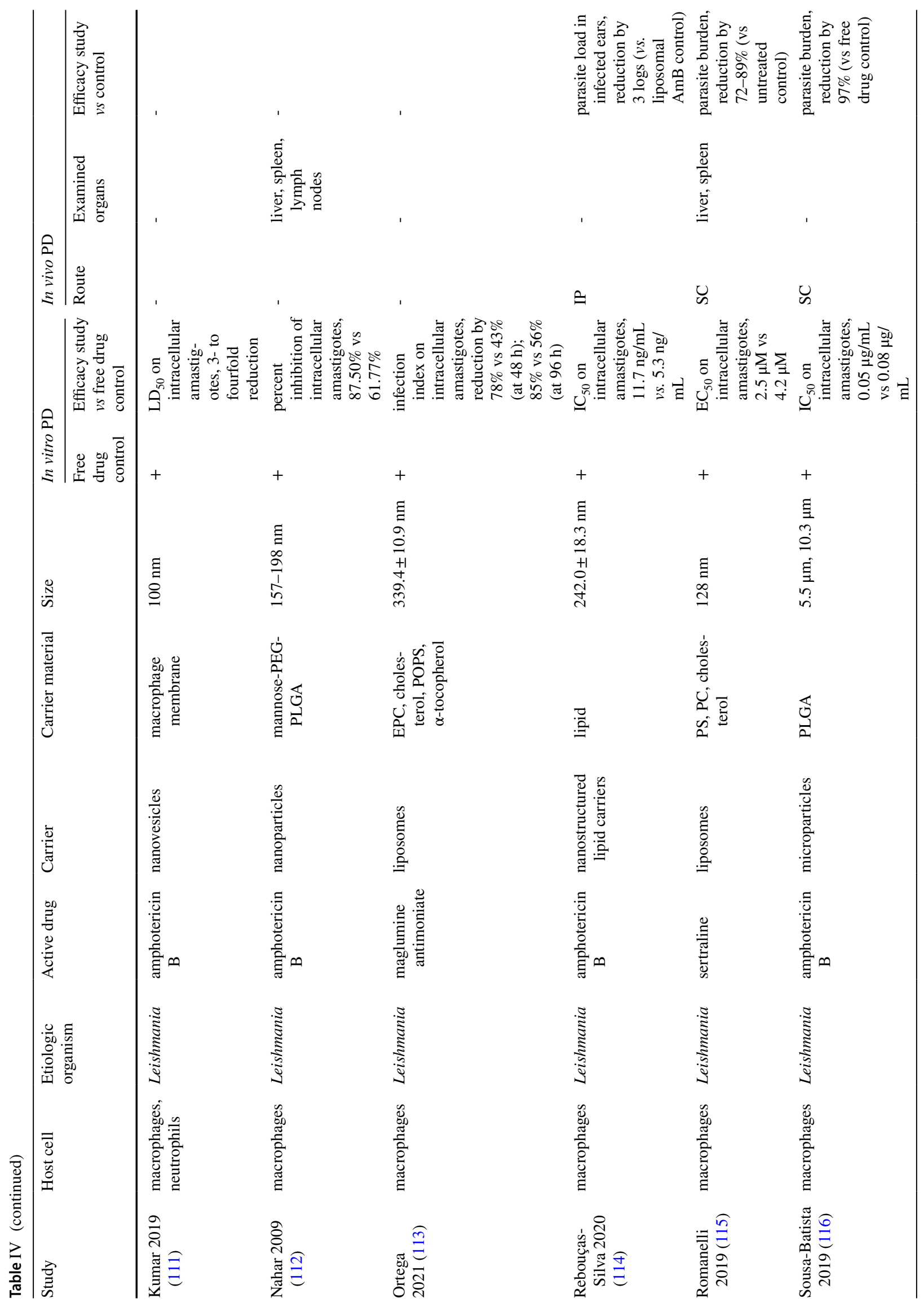




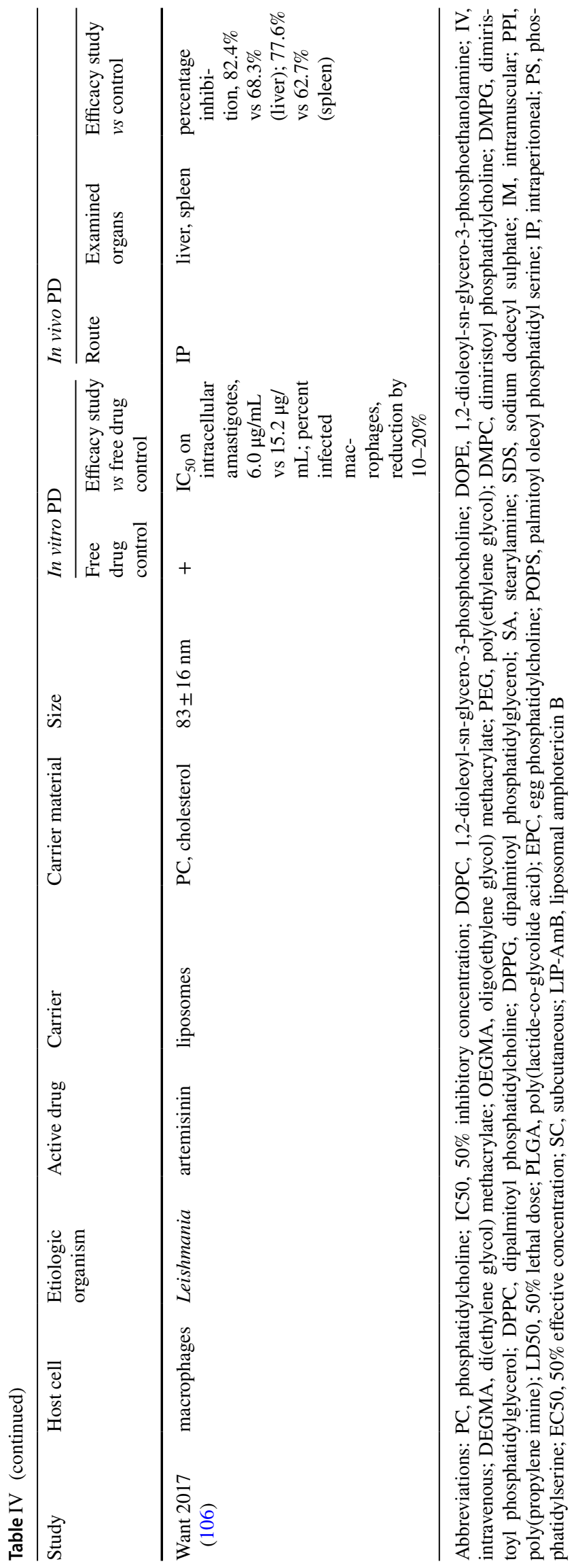


Table V Study Methodologies Used to Assess Intracellular Delivery and Antimicrobial Efficacy

\begin{tabular}{|c|c|c|c|c|}
\hline Study methodologies & $\begin{array}{l}\text { Bacteria } \\
(n=62)\end{array}$ & $\begin{array}{l}\text { Virus } \\
(n=16)\end{array}$ & $\begin{array}{l}\text { Fungus } \\
(n=8)\end{array}$ & $\begin{array}{l}\text { Parasite } \\
(n=15)\end{array}$ \\
\hline \multicolumn{5}{|l|}{ Intracellular delivery study } \\
\hline Microscopy, n (\%) & 45 (72.6) & $11(68.8)$ & $8(100.0)$ & $11(73.3)$ \\
\hline Flow cytometry, n (\%) & $20(32.3)$ & $6(37.5)$ & $5(62.5)$ & $8(53.3)$ \\
\hline \multicolumn{5}{|l|}{ Antimicrobial efficacy study } \\
\hline In vitro $\mathrm{PD}, \mathrm{n}(\%)$ & $49(79.0)$ & $14(87.5)$ & $6(75.0)$ & $11(73.3)$ \\
\hline Microbial burden vs. free drug control, n (\%) & $40(64.5)$ & $5(31.3)$ & $3(37.5)$ & $7(46.7)$ \\
\hline MIC, IC50 or EC50 vs. free drug control, n (\%) & $12(19.4)$ & $7(43.8)$ & $4(50.0)$ & $8(53.3)$ \\
\hline Both $v s$. free drug control, $\mathrm{n}(\%)$ & $9(14.5)$ & $2(12.5)$ & $2(25.0)$ & \\
\hline In vivo $\mathrm{PD}, \mathrm{n}(\%)$ & $18(29.0)$ & $4(25.0)$ & $4(50.0)$ & $8(53.3)$ \\
\hline No evidence of intracellular delivery, n (\%) & 7 (11.3) & $\mathbf{0}(\mathbf{0})$ & $\mathbf{0}(\mathbf{0})$ & $1(6.7)$ \\
\hline
\end{tabular}

Note: No evidence of intracellular delivery is defined when a study was conducted with neither microscopy/flow cytometry nor in vitro PD

Abbreviations: PD, pharmacodynamics; MIC, minimum inhibitory concentration; IC50, $50 \%$ inhibitory concentration; EC50, 50\% effective concentration delivery of the drug or to the additive/synergistic activities of the drug and carrier. Although the blank delivery platform control was not employed as a quality evaluation criterion in this meta-analysis, it would be ideal to include not only free drugs but also drug-free carriers when comparing the PD in future studies.

Our analysis also reveals an access barrier that formulation scientists may face in entering the antimicrobial delivery field. Many organisms of clinical significance require a laboratory with the biosafety level 3 or higher and biocontainment facilities due to the infectious nature of microorganisms (Mycobacterium tuberculosis, Francisella tularensis, Brucella, Ebola, etc.) (126). Non-pathogenic models that share the intracellular residence and drug sensitivity as pathogens of interest will be extremely valuable to drug delivery scientists who intend to assess the effectiveness of delivery systems. For instance, Mycobacterium smegmatis was once considered as a non-pathogenic, fast-growing surrogate of $M$. tuberculosis $(127,128)$. Although $M$. smegmatis was criticized for the differential sensitivity to drugs and stresses and the inability to persist in phagocytes (129), a new strain similar to $M$. tuberculosis in drug sensitivity has been reported in recent literature (130). We expect that growing availability of such non-pathogenic model organisms will help introduce more investigators into the antimicrobial drug delivery field. Animal models are another bottleneck to the translation of new technology. M. tuberculosis has been studied in various preclinical models, including zebrafish, mice, rabbits, guinea pigs, and nonhuman primates, infected with model organisms $(37,131-136)$. The sensitivity to infection, immune responses to the pathogens, and the type of lesions vary with animal models; thus, the choice of animal models depends on the purpose of research (131). In the evaluation of new carriers, mouse models are dominantly used for locating the carriers in organ- and cell levels. However, a recent study shows an example using zebrafish to observe in vivo trafficking of polymersomes to M. marinum-infected macrophages and granulomas with the convenience of optical transparency and fluorescent transgenic lines (37). To determine the effectiveness of new delivery technology in cost- and time-efficient manner, it will be important for drug delivery scientists to develop broader understanding of available animal models and their utility and limitations.

\section{Conclusions}

Substantial advancements have been made in nanotechnology and precision medicine over the last few decades. The present meta-analysis reviewed the quality of carriermedicated antimicrobial delivery studies against intracellular pathogens and revealed that several studies lack essential components of PD efficacy studies. To facilitate the clinical translation of antimicrobial products for intracellular targets, future drug delivery research on intracellular pathogens need to consider the utility and limitations of dominant experimental methodologies and improve the rigor of carrier evaluation.

Supplementary Information The online version contains supplementary material available at https://doi.org/10.1007/s11095-022-03188-z.

ACKNOWLEDGMENTS AND DISCLOUSURES This study was supported by the National Institutes of Health (R01 CA232419, R01 CA258737), Basic Science Research Program through the National Research Foundation of Korea (NRF) grant funded by the Ministry of Science and ICT (No. 2021R1C1C1003735) and by Ajou University re-search fund (S-2021-G0001-00310). The authors report no conflicts of interest in this research. 


\section{References}

1. Prestinaci F, Pezzotti P, Pantosti A. Antimicrobial resistance: a global multifaceted phenomenon. Pathog Glob Health. 2015;109(7):309-18.

2. Thakur A, Mikkelsen H, Jungersen G. Intracellular Pathogens: Host Immunity and Microbial Persistence Strategies. J Immunol Res. 2019;2019:1356540.

3. Price JV, Vance RE. The macrophage paradox. Immunity. 2014;41(5):685-93.

4. Mitchell G, Chen C, Portnoy DA. Strategies Used by Bacteria to Grow in Macrophages. Microbiol Spectr. 2016;4(3).

5. Price LB, Hungate BA, Koch BJ, Davis GS, Liu CM. Colonizing opportunistic pathogens (COPs): The beasts in all of us. PLoS Pathog. 2017;13(8):e1006369.

6. Llor C, Bjerrum L. Antimicrobial resistance: risk associated with antibiotic overuse and initiatives to reduce the problem. Ther Adv Drug Saf. 2014;5(6):229-41.

7. Chaudhary N, Weissman D, Whitehead KA. mRNA vaccines for infectious diseases: principles, delivery and clinical translation. Nat Rev Drug Discov. 2021;20(11):817-38.

8. Wu Z, Li T. Nanoparticle-Mediated Cytoplasmic Delivery of Messenger RNA Vaccines: Challenges and Future Perspectives. Pharm Res. 2021;38(3):473-8.

9. Mehta A, Michler T, Merkel OM. siRNA Therapeutics against Respiratory Viral Infections-What Have We Learned for Potential COVID-19 Therapies? Adv Healthc Mater. 2021;10(7):e2001650.

10. Akinc A, Battaglia G. Exploiting endocytosis for nanomedicines. Cold Spring Harb Perspect Biol. 2013;5(11):a016980.

11. Mba IE, Nweze EI. Nanoparticles as therapeutic options for treating multidrug-resistant bacteria: research progress, challenges, and prospects. World J Microbiol Biotechnol. 2021;37(6):108.

12. Cheng YH, He C, Riviere JE, Monteiro-Riviere NA, Lin Z. Meta-Analysis of Nanoparticle Delivery to Tumors Using a Physiologically Based Pharmacokinetic Modeling and Simulation Approach. ACS Nano. 2020;14(3):3075-95.

13. Barabadi H, Alizadeh A, Ovais M, Ahmadi A, Shinwari ZK, Saravanan M. Efficacy of green nanoparticles against cancerous and normal cell lines: a systematic review and meta-analysis. IET Nanobiotechnol. 2018;12(4):377-91.

14. Pei Y, Yeo Y. Drug delivery to macrophages: Challenges and opportunities. J Control Release. 2016;240:202-11.

15. Hussain A, Singh S, Das SS, Anjireddy K, Karpagam S, Shakeel F. Nanomedicines as Drug Delivery Carriers of Anti-Tubercular Drugs: From Pathogenesis to Infection Control. Curr Drug Deliv. 2019;16(5):400-29.

16. Dahanayake MH, Jayasundera ACA. Nano-based drug delivery optimization for tuberculosis treatment: A review. J Microbiol Methods. 2021;181:106127.

17. Subramaniam S, Joyce P, Thomas N, Prestidge CA. Bioinspired drug delivery strategies for repurposing conventional antibiotics against intracellular infections. Adv Drug Deliv Rev. 2021; $177: 113948$.

18. Lueth P, Haughney SL, Binnebose AM, Mullis AS, PeroutkaBigus N, Narasimhan B, Bellaire BH. Nanotherapeutic provides dose sparing and improved antimicrobial activity against Brucella melitensis infections. J Control Release. 2019;294:288-97.

19. Omolo CA, Megrab NA, Kalhapure RS, Agrawal N, Jadhav M, Mocktar C, Rambharose S, Maduray K, Nkambule B, Govender T. Liposomes with $\mathrm{pH}$ responsive "on and off" switches for targeted and intracellular delivery of antibiotics. J Liposome Res. 2021;31(1):45-63.

20. Afinjuomo F, Barclay TG, Parikh A, Song Y, Chung R, Wang L, Liu L, Hayball JD, Petrovsky N, Garg S. Design and
Characterization of Inulin Conjugate for Improved Intracellular and Targeted Delivery of Pyrazinoic Acid to Monocytes. Pharmaceutics. 2019;11(5).

21. Akbari V, Abedi D, Pardakhty A, Sadeghi-Aliabadi H. Ciprofloxacin nano-niosomes for targeting intracellular infections: an in vitro evaluation. J Nanoparticle Res. 2013;15(4).

22. Ardekani SM, Dehghani A, Ye P, Nguyen KA, Gomes VG. Conjugated carbon quantum dots: Potent nano-antibiotic for intracellular pathogens. J Colloid Interface Sci. 2019;552:378-87.

23. Arshad R, Tabish TA, Kiani MH, Ibrahim IM, Shahnaz G, Rahdar A, Kang M, Pandey S. A Hyaluronic Acid Functionalized Self-Nano-Emulsifying Drug Delivery System (SNEDDS) for Enhancement in Ciprofloxacin Targeted Delivery against Intracellular Infection. Nanomaterials (Basel). 2021;11(5).

24. Brockman SM, Bodas M, Silverberg D, Sharma A, Vij N. Dendrimer-based selective autophagy-induction rescues DeltaF508CFTR and inhibits Pseudomonas aeruginosa infection in cystic fibrosis. PLoS One. 2017;12(9):e0184793.

25. Chokshi NV, Rawal S, Solanki D, Gajjar S, Bora V, Patel BM, Patel MM. Fabrication and Characterization of Surface Engineered Rifampicin Loaded Lipid Nanoparticulate Systems for the Potential Treatment of Tuberculosis: An In vitro and In vivo Evaluation. J Pharm Sci. 2021;110(5):2221-32.

26. Chono S, Tanino T, Seki T, Morimoto K. Efficient drug delivery to alveolar macrophages and lung epithelial lining fluid following pulmonary administration of liposomal ciprofloxacin in rats with pneumonia and estimation of its antibacterial effects. Drug Dev Ind Pharm. 2008;34(10):1090-6.

27. Chono S, Tanino T, Seki T, Morimoto K. Efficient drug targeting to rat alveolar macrophages by pulmonary administration of ciprofloxacin incorporated into mannosylated liposomes for treatment of respiratory intracellular parasitic infections. J Control Release. 2008;127(1):50-8.

28. Chuan J, Li Y, Yang L, Sun X, Zhang Q, Gong T, Zhang Z. Enhanced rifampicin delivery to alveolar macrophages by solid lipid nanoparticles. J Nanoparticle Res. 2013;15(5).

29. Clemens DL, Lee BY, Xue M, Thomas CR, Meng H, Ferris D, Nel AE, Zink JI, Horwitz MA. Targeted intracellular delivery of antituberculosis drugs to Mycobacterium tuberculosis-infected macrophages via functionalized mesoporous silica nanoparticles. Antimicrob Agents Chemother. 2012;56(5):2535-45.

30. Croitoru CD, Mihaiescu DE, Chifiriuc MC, Bolocan A, Bleotu C, Grumezescu AM, Saviuc CM, Lazar V, Curutiu C. Efficiency of gentamicin loaded in bacterial polysaccharides microcapsules against intracellular Gram-positive and Gram-negative invasive pathogens. Rom J Morphol Embryol. 2015;56(4):1417-21.

31. Das D, Chen J, Srinivasan S, Kelly AM, Lee B, Son HN, Radella F, West TE, Ratner DM, Convertine AJ, Skerrett SJ, Stayton PS. Synthetic Macromolecular Antibiotic Platform for Inhalable Therapy against Aerosolized Intracellular Alveolar Infections. Mol Pharm. 2017;14(6):1988-97.

32. de Faria TJ, Roman M, de Souza NM, De Vecchi R, de Assis JV, dos Santos AL, Bechtold IH, Winter N, Soares MJ, Silva LP, De Almeida MV, Bafica A. An isoniazid analogue promotes Mycobacterium tuberculosis-nanoparticle interactions and enhances bacterial killing by macrophages. Antimicrob Agents Chemother. 2012;56(5):2259-67.

33. Dube A, Reynolds JL, Law WC, Maponga CC, Prasad PN, Morse GD. Multimodal nanoparticles that provide immunomodulation and intracellular drug delivery for infectious diseases. Nanomedicine. 2014;10(4):831-8.

34. Ellis T, Chiappi M, Garcia-Trenco A, Al-Ejji M, Sarkar S, Georgiou TK, Shaffer MSP, Tetley TD, Schwander S, Ryan MP, Porter AE. Multimetallic Microparticles Increase the Potency of Rifampicin against Intracellular Mycobacterium tuberculosis. ACS Nano. 2018;12(6):5228-40. 
35. Elnaggar MG, Jiang K, Eldesouky HE, Pei Y, Park J, Yuk SA, Meng F, Dieterly AM, Mohammad HT, Hegazy YA, Tawfeek HM, Abdel-Rahman AA, Aboutaleb AE, Seleem MN, Yeo Y. Antibacterial nanotruffles for treatment of intracellular bacterial infection. Biomaterials. 2020;262:120344.

36. Fahimmunisha BA, Ishwarya R, AlSalhi MS, Devanesan S, Govindarajan M, Vaseeharan B. Green fabrication, characterization and antibacterial potential of zinc oxide nanoparticles using Aloe socotrina leaf extract: A novel drug delivery approach. J Drug Deliv Sci Technol. 2020;55.

37. Fenaroli F, Robertson JD, Scarpa E, Gouveia VM, Di Guglielmo C, De Pace C, Elks PM, Poma A, Evangelopoulos D, Canseco JO, Prajsnar TK, Marriott HM, Dockrell DH, Foster SJ, McHugh TD, Renshaw SA, Marti JS, Battaglia G, Rizzello L. Polymersomes Eradicating Intracellular Bacteria. ACS Nano. 2020;14(7):8287-98.

38. Fierer J, Hatlen L, Lin JP, Estrella D, Mihalko P, Yau-Young A. Successful treatment using gentamicin liposomes of Salmonella dublin infections in mice. Antimicrob Agents Chemother. 1990;34(2):343-8.

39. Franch O, Gutierrez-Corbo C, Dominguez-Asenjo B, Boesen T, Jensen PB, Nejsum LN, Keller JG, Nielsen SP, Singh PR, Jha RK, Nagaraja V, Balana-Fouce R, Ho YP, Reguera RM, Knudsen BR. DNA flowerstructure co-localizes with human pathogens in infected macrophages. Nucleic Acids Res. 2020;48(11):6081-91.

40. Gao F, Xu L, Yang B, Fan F, Yang L. Kill the Real with the Fake: Eliminate Intracellular Staphylococcus aureus Using Nanoparticle Coated with Its Extracellular Vesicle Membrane as ActiveTargeting Drug Carrier. ACS Infect Dis. 2019;5(2):218-27.

41. Gaspar MM, Calado S, Pereira J, Ferronha H, Correia I, Castro $\mathrm{H}$, Tomas AM, Cruz ME. Targeted delivery of paromomycin in murine infectious diseases through association to nano lipid systems. Nanomedicine. 2015;11(7):1851-60.

42. Gnanadhas DP, Ben Thomas M, Elango M, Raichur AM, Chakravortty D. Chitosan-dextran sulphate nanocapsule drug delivery system as an effective therapeutic against intraphagosomal pathogen Salmonella. J Antimicrob Chemother. 2013;68(11):2576-86.

43. Heck JG, Rox K, Lunsdorf H, Luckerath T, Klaassen N, Medina E, Goldmann O, Feldmann C. Zirconyl Clindamycinphosphate Antibiotic Nanocarriers for Targeting Intracellular Persisting Staphylococcus aureus. ACS Omega. 2018;3(8):8589-94.

44. Hlaka L, Rosslee MJ, Ozturk M, Kumar S, Parihar SP, Brombacher F, Khalaf AI, Carter KC, Scott FJ, Suckling CJ, Guler R. Evaluation of minor groove binders (MGBs) as novel antimycobacterial agents and the effect of using non-ionic surfactant vesicles as a delivery system to improve their efficacy. J Antimicrob Chemother. 2017;72(12):3334-41.

45. Horsley H, Owen J, Browning R, Carugo D, Malone-Lee J, Stride $\mathrm{E}$, Rohn JL. Ultrasound-activated microbubbles as a novel intracellular drug delivery system for urinary tract infection. J Control Release. 2019;301:166-75.

46. Hsu CY, Sung CT, Aljuffali IA, Chen CH, Hu KY, Fang JY. Intravenous anti-MRSA phosphatiosomes mediate enhanced affinity to pulmonary surfactants for effective treatment of infectious pneumonia. Nanomedicine. 2018;14(2):215-25.

47. Imbuluzqueta E, Lemaire S, Gamazo C, Elizondo E, Ventosa N, Veciana J, Van Bambeke F, Blanco-Prieto MJ. Cellular pharmacokinetics and intracellular activity against Listeria monocytogenes and Staphylococcus aureus of chemically modified and nanoencapsulated gentamicin. J Antimicrob Chemother. 2012;67(9):2158-64.

48. Imbuluzqueta E, Gamazo C, Lana H, Campanero MA, Salas D, Gil AG, Elizondo E, Ventosa N, Veciana J, Blanco-Prieto MJ. Hydrophobic gentamicin-loaded nanoparticles are effective against Brucella melitensis infection in mice. Antimicrob Agents Chemother. 2013;57(7):3326-33.
49. Jankie S, Johnson J, Adebayo AS, Pillai GK, Pinto Pereira LM. Efficacy of Levofloxacin Loaded Nonionic Surfactant Vesicles (Niosomes) in a Model of Pseudomonas aeruginosa Infected Sprague Dawley Rats. Adv Pharmacol Pharm Sci. 2020;2020:8815969.

50. Kiruthika V, Maya S, Suresh MK, Kumar VA, Jayakumar R, Biswas R. Comparative efficacy of chloramphenicol loaded chondroitin sulfate and dextran sulfate nanoparticles to treat intracellular Salmonella infections. Colloids Surf B Biointerfaces. 2015;127:33-40.

51. Labbaf S, Horsley H, Chang MW, Stride E, Malone-Lee J, Edirisinghe M, Rohn JL. An encapsulated drug delivery system for recalcitrant urinary tract infection. J R Soc Interface. 2013;10(89):20130747.

52. Labouta HI, Menina S, Kochut A, Gordon S, Geyer R, Dersch $\mathrm{P}$, Lehr CM. Bacteriomimetic invasin-functionalized nanocarriers for intracellular delivery. J Control Release. 2015;220(Pt A):414-24.

53. Lacoma A, Uson L, Mendoza G, Sebastian V, Garcia-Garcia E, Muriel-Moreno B, Dominguez J, Arruebo M, Prat C. Novel intracellular antibiotic delivery system against Staphylococcus aureus: cloxacillin-loaded poly(d, l-lactide-co-glycolide) acid nanoparticles. Nanomedicine (Lond). 2020;15(12):1189-203.

54. Lau WK, Dharmasena D, Horsley H, Jafari NV, Malone-Lee J, Stride E, Edirisinghe M, Rohn JL. Novel antibiotic-loaded particles conferring eradication of deep tissue bacterial reservoirs for the treatment of chronic urinary tract infection. J Control Release. 2020;328:490-502.

55. Lee BY, Li Z, Clemens DL, Dillon BJ, Hwang AA, Zink JI, Horwitz MA. Redox-Triggered Release of Moxifloxacin from Mesoporous Silica Nanoparticles Functionalized with Disulfide Snap-Tops Enhances Efficacy Against Pneumonic Tularemia in Mice. Small. 2016;12(27):3690-702.

56. Lunn AM, Unnikrishnan M, Perrier S. Dual pH-Responsive Macrophage-Targeted Isoniazid Glycoparticles for Intracellular Tuberculosis Therapy. Biomacromolecules. 2021.

57. Maji R, Omolo CA, Agrawal N, Maduray K, Hassan D, Mokhtar C, Mackhraj I, Govender T. pH-Responsive Lipid-Dendrimer Hybrid Nanoparticles: An Approach To Target and Eliminate Intracellular Pathogens. Mol Pharm. 2019;16(11):4594-609.

58. Maya S, Indulekha S, Sukhithasri V, Smitha KT, Nair SV, Jayakumar R, Biswas R. Efficacy of tetracycline encapsulated O-carboxymethyl chitosan nanoparticles against intracellular infections of Staphylococcus aureus. Int J Biol Macromol. 2012;51(4):392-9.

59. Mishra MK, Kotta K, Hali M, Wykes S, Gerard HC, Hudson AP, Whittum-Hudson JA, Kannan RM. PAMAM dendrimer-azithromycin conjugate nanodevices for the treatment of Chlamydia trachomatis infections. Nanomedicine. 2011;7(6):935-44.

60. Monsel A, Zhu YG, Gennai S, Hao Q, Hu S, Rouby JJ, Rosenzwajg M, Matthay MA, Lee JW. Therapeutic Effects of Human Mesenchymal Stem Cell-derived Microvesicles in Severe Pneumonia in Mice. Am J Respir Crit Care Med. 2015;192(3):324-36.

61. Montanari E, D’Arrigo G, Di Meo C, Virga A, Coviello T, Passariello C, Matricardi P. Chasing bacteria within the cells using levofloxacin-loaded hyaluronic acid nanohydrogels. Eur J Pharm Biopharm. 2014;87(3):518-23.

62. Pei Y, Mohamed MF, Seleem MN, Yeo Y. Particle engineering for intracellular delivery of vancomycin to methicillin-resistant Staphylococcus aureus (MRSA)-infected macrophages. J Control Release. 2017;267:133-43.

63. Pi J, Shen L, Shen H, Yang E, Wang W, Wang R, Huang D, Lee BS, Hu C, Chen C, Jin H, Cai J, Zeng G, Chen ZW. Mannosylated graphene oxide as macrophage-targeted delivery system for enhanced intracellular M.tuberculosis killing efficiency. Mater Sci Eng C Mater Biol Appl. 2019;103:109777. 
64. Prabhu P, Fernandes T, Chaubey P, Kaur P, Narayanan S, Vk $R$, Sawarkar SP. Mannose-conjugated chitosan nanoparticles for delivery of Rifampicin to Osteoarticular tuberculosis. Drug Deliv Transl Res. 2021;11(4):1509-19.

65. Pumerantz A, Muppidi K, Agnihotri S, Guerra C, Venketaraman V, Wang J, Betageri G. Preparation of liposomal vancomycin and intracellular killing of meticillin-resistant Staphylococcus aureus (MRSA). Int J Antimicrob Agents. 2011;37(2):140-4.

66. Ranjan A, Pothayee N, Seleem M, Jain N, Sriranganathan N, Riffle JS, Kasimanickam R. Drug delivery using novel nanoplexes against a Salmonella mouse infection model. J Nanopart Res. 2009;12(3):905-14.

67. Rodrigues S, Cunha L, Kollan J, Neumann PR, Rosa da Costa AM, Dailey LA, Grenha A. Cytocompatibility and cellular interactions of chondroitin sulfate microparticles designed for inhaled tuberculosis treatment. Eur J Pharm Biopharm. 2021;163:171-8.

68. Sava Gallis DF, Butler KS, Agola JO, Pearce CJ, McBride AA. Antibacterial Countermeasures via Metal-Organic FrameworkSupported Sustained Therapeutic Release. ACS Appl Mater Interfaces. 2019;11(8):7782-91.

69. Smitha KT, Nisha N, Maya S, Biswas R, Jayakumar R. Delivery of rifampicin-chitin nanoparticles into the intracellular compartment of polymorphonuclear leukocytes. Int J Biol Macromol. 2015;74:36-43.

70. Subramaniam S, Thomas N, Gustafsson H, Jambhrunkar M, Kidd SP, Prestidge CA. Rifampicin-Loaded Mesoporous Silica Nanoparticles for the Treatment of Intracellular Infections. Antibiotics (Basel). 2019;8(2).

71. Uskokovic V, Desai TA. Simultaneous bactericidal and osteogenic effect of nanoparticulate calcium phosphate powders loaded with clindamycin on osteoblasts infected with Staphylococcus aureus. Mater Sci Eng C Mater Biol Appl. 2014;37:210-22.

72. Vaghasiya K, Eram A, Sharma A, Ray E, Adlakha S, Verma RK. Alginate Microspheres Elicit Innate M1-Inflammatory Response in Macrophages Leading to Bacillary Killing. AAPS PharmSciTech. 2019;20(6):241.

73. Vieira AC, Magalhaes J, Rocha S, Cardoso MS, Santos SG, Borges M, Pinheiro M, Reis S. Targeted macrophages delivery of rifampicin-loaded lipid nanoparticles to improve tuberculosis treatment. Nanomedicine (Lond). 2017;12(24):2721-36.

74. Vyas SP, Kannan ME, Jain S, Mishra V, Singh P. Design of liposomal aerosols for improved delivery of rifampicin to alveolar macrophages. Int J Pharm. 2004;269(1):37-49.

75. Xiong MH, Bao Y, Yang XZ, Wang YC, Sun B, Wang J. Lipasesensitive polymeric triple-layered nanogel for "on-demand" drug delivery. J Am Chem Soc. 2012;134(9):4355-62.

76. Yang J, Li Y, Liu E, Xininigen TW, Bai W, Han R. Using rifapentine - hen egg lipoprotein conjugate as macrophage-targeted drug delivery carrier against intracellular Staphylococcus aureus. Drug Deliv. 2015;22(1):111-6.

77. Yu S, Yuan H, Chai G, Peng K, Zou P, Li X, Li J, Zhou F, Chan HK, Zhou QT. Optimization of inhalable liposomal powder formulations and evaluation of their in vitro drug delivery behavior in Calu-3 human lung epithelial cells. Int J Pharm. 2020;586:119570.

78. Zaki NM, Hafez MM. Enhanced antibacterial effect of ceftriaxone sodium-loaded chitosan nanoparticles against intracellular Salmonella typhimurium. AAPS PharmSciTech. 2012;13(2):411-21.

79. Zhang Y, Liang RJ, Xu JJ, Shen LF, Gao JQ, Wang XP, Wang $\mathrm{NN}$, Shou D, Hu Y. Efficient induction of antimicrobial activity with vancomycin nanoparticle-loaded poly(trimethylene carbonate) localized drug delivery system. Int J Nanomed. 2017;12:1201-14.
80. Hu CJ, Chen YT, Fang ZS, Chang WS, Chen HW. Antiviral efficacy of nanoparticulate vacuolar ATPase inhibitors against influenza virus infection. Int J Nanomedicine. 2018;13:8579-93.

81. Chandra PK, Kundu AK, Hazari S, Chandra S, Bao L, Ooms T, Morris GF, Wu T, Mandal TK, Dash S. Inhibition of hepatitis $\mathrm{C}$ virus replication by intracellular delivery of multiple siRNAs by nanosomes. Mol Ther. 2012;20(9):1724-36.

82. Creighton RL, Suydam IT, Ebner ME, Afunugo WE, Bever AM, Cao S, Jiang Y, Woodrow KA. Sustained Intracellular Raltegravir Depots Generated with Prodrugs Designed for Nanoparticle Delivery. ACS Biomater Sci Eng. 2019;5(8):4013-22.

83. das Neves J, Michiels J, Arien KK, Vanham G, Amiji M, Bahia MF, Sarmento B. Polymeric nanoparticles affect the intracellular delivery, antiretroviral activity and cytotoxicity of the microbicide drug candidate dapivirine. Pharm Res. 2012;29(6):1468-84.

84. Donalisio M, Argenziano M, Ritta M, Bastiancich C, Civra A, Lembo D, Cavalli R. Acyclovir-loaded sulfobutyl ether-betacyclodextrin decorated chitosan nanodroplets for the local treatment of HSV-2 infections. Int J Pharm. 2020;587:119676.

85. Geisbert TW, Lee AC, Robbins M, Geisbert JB, Honko AN, Sood V, Johnson JC, de Jong S, Tavakoli I, Judge A, Hensley LE, Maclachlan I. Postexposure protection of non-human primates against a lethal Ebola virus challenge with RNA interference: a proof-of-concept study. Lancet. 2010;375(9729):1896-905.

86. Gong Y, Chowdhury P, Nagesh PKB, Rahman MA, Zhi K, Yallapu MM, Kumar S. Novel elvitegravir nanoformulation for drug delivery across the blood-brain barrier to achieve HIV-1 suppression in the CNS macrophages. Sci Rep. 2020;10(1):3835.

87. Guedj AS, Kell AJ, Barnes M, Stals S, Goncalves D, Girard D, Lavigne C. Preparation, characterization, and safety evaluation of poly(lactide-co-glycolide) nanoparticles for protein delivery into macrophages. Int J Nanomedicine. 2015;10:5965-79.

88. Hillaireau H, Dereuddre-Bosquet N, Skanji R, Bekkara-Aounallah F, Caron J, Lepetre S, Argote S, Bauduin L, Yousfi R, RogezKreuz C, Desmaele D, Rousseau B, Gref R, Andrieux K, Clayette $\mathrm{P}$, Couvreur P. Anti-HIV efficacy and biodistribution of nucleoside reverse transcriptase inhibitors delivered as squalenoylated prodrug nanoassemblies. Biomaterials. 2013;34(20):4831-8.

89. Jiang Y, Cao S, Bright DK, Bever AM, Blakney AK, Suydam IT, Woodrow KA. Nanoparticle-Based ARV Drug Combinations for Synergistic Inhibition of Cell-Free and Cell-Cell HIV Transmission. Mol Pharm. 2015;12(12):4363-74.

90. Mandal S, Prathipati PK, Belshan M, Destache CJ. A potential long-acting bictegravir loaded nano-drug delivery system for HIV-1 infection: A proof-of-concept study. Antiviral Res. 2019;167:83-8.

91. Mazzaglia A, Scala A, Sortino G, Zagami R, Zhu Y, Sciortino MT, Pennisi R, Pizzo MM, Neri G, Grassi G, Piperno A. Intracellular trafficking and therapeutic outcome of multiwalled carbon nanotubes modified with cyclodextrins and polyethylenimine. Colloids Surf B Biointerfaces. 2018;163:55-63.

92. Thi EP, Mire CE, Lee AC, Geisbert JB, Zhou JZ, Agans KN, Snead NM, Deer DJ, Barnard TR, Fenton KA, MacLachlan I, Geisbert TW. Lipid nanoparticle siRNA treatment of Ebola-virus-Makona-infected nonhuman primates. Nature. 2015;521(7552):362-5.

93. Timin AS, Muslimov AR, Petrova AV, Lepik KV, Okilova MV, Vasin AV, Afanasyev BV, Sukhorukov GB. Hybrid inorganicorganic capsules for efficient intracellular delivery of novel siRNAs against influenza A (H1N1) virus infection. Sci Rep. 2017;7(1):102.

94. Wohl BM, Smith AA, Jensen BE, Zelikin AN. Macromolecular (pro)drugs with concurrent direct activity against the hepatitis C virus and inflammation. J Control Release. 2014;196:197-207. 
95. Zhang J, Garrison JC, Poluektova LY, Bronich TK, Osna NA. Liver-targeted antiviral peptide nanocomplexes as potential antiHCV therapeutics. Biomaterials. 2015;70:37-47.

96. Batista-Duharte A, Lastre M, Romeu B, Portuondo DL, TellezMartinez D, Manente FA, Perez O, Carlos IZ. Antifungal and immunomodulatory activity of a novel cochleate for amphotericin B delivery against Sporothrix schenckii. Int Immunopharmacol. 2016;40:277-87.

97. Cheng L, Niu MM, Yan T, Ma Z, Huang K, Yang L, Zhong X, Li C. Bioresponsive micro-to-nano albumin-based systems for targeted drug delivery against complex fungal infections. Acta Pharm Sin B. 2021;11(10):3220-30.

98. Diez-Orejas R, Feito MJ, Cicuendez M, Casarrubios L, Rojo JM, Portoles MT. Graphene oxide nanosheets increase Candida albicans killing by pro-inflammatory and reparative peritoneal macrophages. Colloids Surf B Biointerfaces. 2018;171:250-9.

99. Diez-Orejas R, Casarrubios L, Feito MJ, Rojo JM, Vallet-Regi $\mathrm{M}$, Arcos D, Portoles MT. Effects of mesoporous SiO2-CaO nanospheres on the murine peritoneal macrophages/Candidaalbicans interface. Int Immunopharmacol. 2021;94:107457.

100. Li X, Huang R, Tang FK, Li WC, Wong SSW, Leung KC, Jin L. Red-Emissive Guanylated Polyene-Functionalized Carbon Dots Arm Oral Epithelia against Invasive Fungal Infections. ACS Appl Mater Interfaces. 2019;11(50):46591-603.

101. Mejia SP, Sanchez A, Vasquez V, Orozco J. Functional Nanocarriers for Delivering Itraconazole Against Fungal Intracellular Infections. Front Pharmacol. 2021;12:685391.

102. Shao K, Zhang Y, Ding N, Huang S, Wu J, Li J, Yang C, Leng Q, Ye L, Lou J, Zhu L, Jiang C. Functionalized nanoscale micelles with brain targeting ability and intercellular microenvironment biosensitivity for anti-intracranial infection applications. Adv Healthc Mater. 2015;4(2):291-300.

103. Xie J, Shen Q, Huang K, Zheng T, Cheng L, Zhang Z, Yu Y, Liao G, Wang X, Li C. Oriented Assembly of Cell-Mimicking Nanoparticles via a Molecular Affinity Strategy for Targeted Drug Delivery. ACS Nano. 2019;13(5):5268-77.

104. Gupta PK, Jaiswal AK, Asthana S, Dube A, Mishra PR. Antigen presenting cells targeting and stimulation potential of lipoteichoic acid functionalized lipo-polymerosome: a chemoimmunotherapeutic approach against intracellular infectious disease. Biomacromol. 2015;16(4):1073-87.

105. Jain K, Verma AK, Mishra PR, Jain NK. Surface-engineered dendrimeric nanoconjugates for macrophage-targeted delivery of amphotericin B: formulation development and in vitro and in vivo evaluation. Antimicrob Agents Chemother. 2015;59(5):2479-87.

106. Want MY, Islammudin M, Chouhan G, Ozbak HA, Hemeg HA, Chattopadhyay AP, Afrin F. Nanoliposomal artemisinin for the treatment of murine visceral leishmaniasis. Int J Nanomedicine. 2017;12:2189-204

107. Borborema SE, Schwendener RA, Osso JA Jr, de Andrade HF Jr, do Nascimento N. Uptake and antileishmanial activity of meglumine antimoniate-containing liposomes in Leishmania (Leishmania) major-infected macrophages. Int J Antimicrob Agents. 2011;38(4):341-7.

108. de Oliveira JK, Ueda-Nakamura T, Correa AG, Petrilli R, Lopez RFV, Nakamura CV, Auzely-Velty R. Liposome-based nanocarrier loaded with a new quinoxaline derivative for the treatment of cutaneous leishmaniasis. Mater Sci Eng C Mater Biol Appl. 2020;110:110720.

109. Fernandes Stefanello T, Szarpak-Jankowska A, Appaix F, Louage B, Hamard L, De Geest BG, van der Sanden B, Nakamura CV, Auzely-Velty R. Thermoresponsive hyaluronic acid nanogels as hydrophobic drug carrier to macrophages. Acta Biomater. 2014;10(11):4750-8.

110. Heidari-Kharaji M, Taheri T, Doroud D, Habibzadeh S, Badirzadeh A, Rafati S. Enhanced paromomycin efficacy by solid lipid nanoparticle formulation against Leishmania in mice model. Parasite Immunol. 2016;38(10):599-608.

111. Kumar P, Bose PP. Macrophage ghost entrapped amphotericin B: a novel delivery strategy towards experimental visceral leishmaniasis. Drug Deliv Transl Res. 2019;9(1):249-59.

112. Nahar M, Jain NK. Preparation, characterization and evaluation of targeting potential of amphotericin B-loaded engineered PLGA nanoparticles. Pharm Res. 2009;26(12):2588-98.

113. Ortega V, Radaic A, de Jesus MB, de Paula E, Giorgio S. Improved efficacy of meglumine antimoniate incorporated in anionic liposomes against Leishmania infantum infecting canine macrophages. J Pharm Pharmacol. 2021.

114. Reboucas-Silva J, Tadini MC, Devequi-Nunes D, Mansur AL, Silveira-Mattos PS, de Oliveira CI, Formiga FR, Berretta AA, Marquele-Oliveira F, Borges VM. Evaluation of in vitro and in vivo Efficacy of a Novel Amphotericin B-Loaded Nanostructured Lipid Carrier in the Treatment of Leishmania braziliensis Infection. Int J Nanomedicine. 2020;15:8659-72.

115. Romanelli MM, da Costa-Silva TA, Cunha-Junior E, Dias Ferreira D, Guerra JM, Galisteo AJ Jr, Pinto EG, Barbosa LRS, Torres-Santos EC, Tempone AG. Sertraline Delivered in Phosphatidylserine Liposomes Is Effective in an Experimental Model of Visceral Leishmaniasis. Front Cell Infect Microbiol. 2019;9:353.

116. Sousa-Batista AJ, Pacienza-Lima W, Re MI, Rossi-Bergmann B. Novel and safe single-dose treatment of cutaneous leishmaniasis with implantable amphotericin B-loaded microparticles. Int J Parasitol Drugs Drug Resist. 2019;11:148-55.

117. Torres-Guerrero E, Quintanilla-Cedillo MR, Ruiz-Esmenjaud J, Arenas R. Leishmaniasis: a review. F1000Res. 2017;6:750.

118. Ghorbani M, Farhoudi R. Leishmaniasis in humans: drug or vaccine therapy? Drug Des Devel Ther. 2018;12:25-40.

119. Stafford JL, Neumann NF, Belosevic M. Macrophage-mediated innate host defense against protozoan parasites. Crit Rev Microbiol. 2002;28(3):187-248.

120. Kato KC, Morais-Teixeira E, Reis PG, Silva-Barcellos NM, Salaun P, Campos PP, Dias Correa-Junior J, Rabello A, Demicheli C, Frezard F. Hepatotoxicity of pentavalent antimonial drug: possible role of residual $\mathrm{Sb}(\mathrm{III})$ and protective effect of ascorbic acid. Antimicrob Agents Chemother. 2014;58(1):481-8.

121. Weiss G, Schaible UE. Macrophage defense mechanisms against intracellular bacteria. Immunol Rev. 2015;264(1):182-203.

122. Xu P, Gullotti E, Tong L, Highley CB, Errabelli DR, Hasan T, Cheng JX, Kohane DS, Yeo Y. Intracellular drug delivery by poly(lactic-co-glycolic acid) nanoparticles, revisited. Mol Pharm. 2009;6(1):190-201.

123. Abouelmagd SA, Sun B, Chang AC, Ku YJ, Yeo Y. Release kinetics study of poorly water-soluble drugs from nanoparticles: are we doing it right? Mol Pharm. 2015;12(3):997-1003.

124. Yilmaz Atay H. Antibacterial Activity of Chitosan-Based Systems. In. Functional Chitosan; 2019. p. 457-489.

125. Liu M, Liu Y, Cao MJ, Liu GM, Chen Q, Sun L, Chen H. Antibacterial activity and mechanisms of depolymerized fucoidans isolated from Laminaria japonica. Carbohydr Polym. 2017;172:294-305.

126. Biosafety in microbiological and biomedical laboratories, 6th edition. Centers for Disease Control and Prevention, National Institutes of Health. 2020.

127. Reyrat JM, Kahn D. Mycobacterium smegmatis: an absurd model for tuberculosis? Trends Microbiol. 2001;9(10):472-4.

128. Chaturvedi V, Dwivedi N, Tripathi RP, Sinha S. Evaluation of Mycobacterium smegmatis as a possible surrogate screen for selecting molecules active against multi-drug resistant Mycobacterium tuberculosis. J Gen Appl Microbiol. 2007;53(6):333-7.

129. Barry CE. Mycobacterium smegmatis: an absurd model for tuberculosis? Trends Microbiol (Regul Ed). 2001;9(10):473-4. 
130. Lelovic N, Mitachi K, Yang J, Lemieux MR, Ji Y, Kurosu M. Application of Mycobacterium smegmatis as a surrogate to evaluate drug leads against Mycobacterium tuberculosis. J Antibiot (Tokyo). 2020;73(11):780-9.

131. Singh AK, Gupta UD. Animal models of tuberculosis: Lesson learnt. Indian J Med Res. 2018;147(5):456-63.

132. Harjula SE, Saralahti AK, Ojanen MJT, Rantapero T, UusiMakela MIE, Nykter M, Lohi O, Parikka M, Ramet M. Characterization of immune response against Mycobacterium marinum infection in the main hematopoietic organ of adult zebrafish (Danio rerio). Dev Comp Immunol. 2020;103:103523.

133. Prouty MG, Correa NE, Barker LP, Jagadeeswaran P, Klose KE. Zebrafish-Mycobacterium marinum model for mycobacterial pathogenesis. FEMS Microbiol Lett. 2003;225(2):177-82.
134. Parikka M, Hammaren MM, Harjula SK, Halfpenny NJ, Oksanen KE, Lahtinen MJ, Pajula ET, Iivanainen A, Pesu M, Ramet M. Mycobacterium marinum causes a latent infection that can be reactivated by gamma irradiation in adult zebrafish. PLoS Pathog. 2012;8(9):e1002944.

135. Tobin DM, Ramakrishnan L. Comparative pathogenesis of Mycobacterium marinum and Mycobacterium tuberculosis. Cell Microbiol. 2008;10(5):1027-39.

136. Myllymaki H, Bauerlein CA, Ramet M. The Zebrafish Breathes New Life into the Study of Tuberculosis. Front Immunol. 2016;7:196.

Publisher's Note Springer Nature remains neutral with regard to jurisdictional claims in published maps and institutional affiliations. 